OPEN ACCESS

Edited by:

Vincent Kam Wai Wong,

Macau University of Science and

Technology, Macao, SAR China

Reviewed by:

Zeng Nan,

Chengdu University of Traditional

Chinese Medicine, China

Vuyisile Samuel Thibane,

University of South Africa, South Africa

Yan Tong,

Southwest Jiaotong University, China

*Correspondence: Jianming Wu

jianmingwu@swmu.edu.cn

Wenjun Zou

zouwenjun@163.com

Jing Zeng

zengjing@swmu.edu.cn

${ }^{\dagger}$ These authors have contributed equally to this work

Specialty section:

This article was submitted to

Ethnopharmacology,

a section of the journal

Frontiers in Pharmacology

Received: 30 July 2021 Accepted: 06 September 2021 Published: 20 September 2021

Citation:

Zhou P, Li J, Chen Q, Wang L, Yang J, Wu A, Jiang N, Liu Y, Chen J, Zou W, Zeng $J$ and Wu J (2021) A

Comprehensive Review of Genus

Sanguisorba: Traditional Uses,

Chemical Constituents and

Medical Applications.

Front. Pharmacol. 12:750165.

doi: 10.3389/fphar.2021.750165

\section{A Comprehensive Review of Genus Sanguisorba: Traditional Uses, Chemical Constituents and Medical Applications}

\author{
Ping Zhou ${ }^{1 \dagger}$, Jingyan $\mathrm{Li}^{2,3 \dagger}$, Qi Chen ${ }^{4 \dagger}$, Long Wang ${ }^{2,5}$, Jing Yang ${ }^{2,5}$, Anguo $\mathrm{Wu}^{2,5}$, \\ Nan Jiang ${ }^{2,3}$, Yuanzhi Liu ${ }^{2,3}$, Jianping Chen ${ }^{6}$, Wenjun Zou ${ }^{1 \star}$, Jing Zeng ${ }^{2 \star}$ and Jianming $W^{2,5 *}$ \\ ${ }^{1}$ Department of Chinese Materia Medica, School of Pharmacy, Chengdu University of Traditional Chinese Medicine, Chengdu, \\ China, ${ }^{2}$ School of Pharmacy, Southwest Medical University, Luzhou, China, ${ }^{3}$ Department of Medical Technology, Faculty of \\ Associated Medical Sciences, Chiang Mai University, Chiang Mai, Thailand, ${ }^{4}$ Department of Endocrinology and Metabolism, The \\ Affiliated Hospital of Southwest Medical University, Luzhou, China, ${ }^{5}$ Education Ministry Key Laboratory of Medical \\ Electrophysiology, Sichuan Key Medical Laboratory of New Drug Discovery and Druggability Evaluation, Luzhou Key Laboratory \\ of Activity Screening and Druggability Evaluation for Chinese Materia Medica, Southwest Medical University, Luzhou, China, \\ ${ }^{6}$ School of Chinese Medicine, The University of Hong Kong, Hong Kong, Hong Kong, SAR China
}

Genus Sanguisorba (family: Rosaceae) comprises nearly 148 species, distributed widely across the temperate and subtropical regions of the Northern Hemisphere. Sanguisorba officinalis L. (S. officinalis) has been used as a hemostatic and scald treating medicine in China for a long time. Numerous studies have demonstrated that plant extracts or monomers from S. officinalis exhibit several pharmacological effects, such as anticancer, anti-virus, anti-inflammation, anti-bacteria, neuroprotective and hepatoprotective effects. The other species of genus Sanguisorba are also being studied by researchers worldwide. Sanguisorba minor Scop. (S. minor), as an edible wild plant, is a common ingredient of the Mediterranean diet, and its young shoots and leaves are often mixed with traditional vegetables and consumed as salad. Reports on genus Sanguisorba available in the current literature were collected from Google Scholar, Web of Science, Springer, and PubMed. The Plant List (http://www.theplantlist.org./tpl1. 1/search?q=Sanguisorba), International Plant Name Index (https://www.ipni.org/? q=Sanguisorba) and Kew Botanical Garden (http://powo.science.kew.org/) were used for obtaining the scientific names and information on the subspecies and cultivars. In recent years, several in vivo and in vitro experiments have been conducted to reveal the active components and effective monomers of $S$. officinalis and $S$. minor. To date, more than 270 compounds have been isolated and identified so far from the species belonging to genus Sanguisorba. Numerous reports on the chemical constituents, pharmacologic effects, and toxicity of genus Sanguisorba are available in the literature. This review provides a comprehensive understanding of the current traditional applications of plants, which are supported by a large number of scientific experiments. Owing to these promising properties, this species is used in the treatment of various diseases, including influenza virus infection, inflammation, Alzheimer's disease, type 2 diabetes and leukopenia caused by bone marrow suppression. Moreover, the rich contents and biological effects of $S$. officinalis and S. minor facilitate these applications in dietary supplements and cosmetics. 
Therefore, the purpose of this review is to summarize the recent advances in the traditional uses, chemical constituents, pharmacological effects and clinical applications of genus Sanguisorba. The present comprehensive review may provide new insights for the future research on genus Sanguisorba.

Keywords: genus Sanguisorba, Sanguisorba officinalis L, Sanguisorba minor Scop, chemical constituents, medical applications, traditional uses

\section{INTRODUCTION}

There is a huge reservoir of compounds in nature that might be useful in drug discovery (Chin et al., 2006). According to a report by the World Health Organization, approximately $80 \%$ of the world's population continues to rely on botanical medicine (Ekor, 2014).

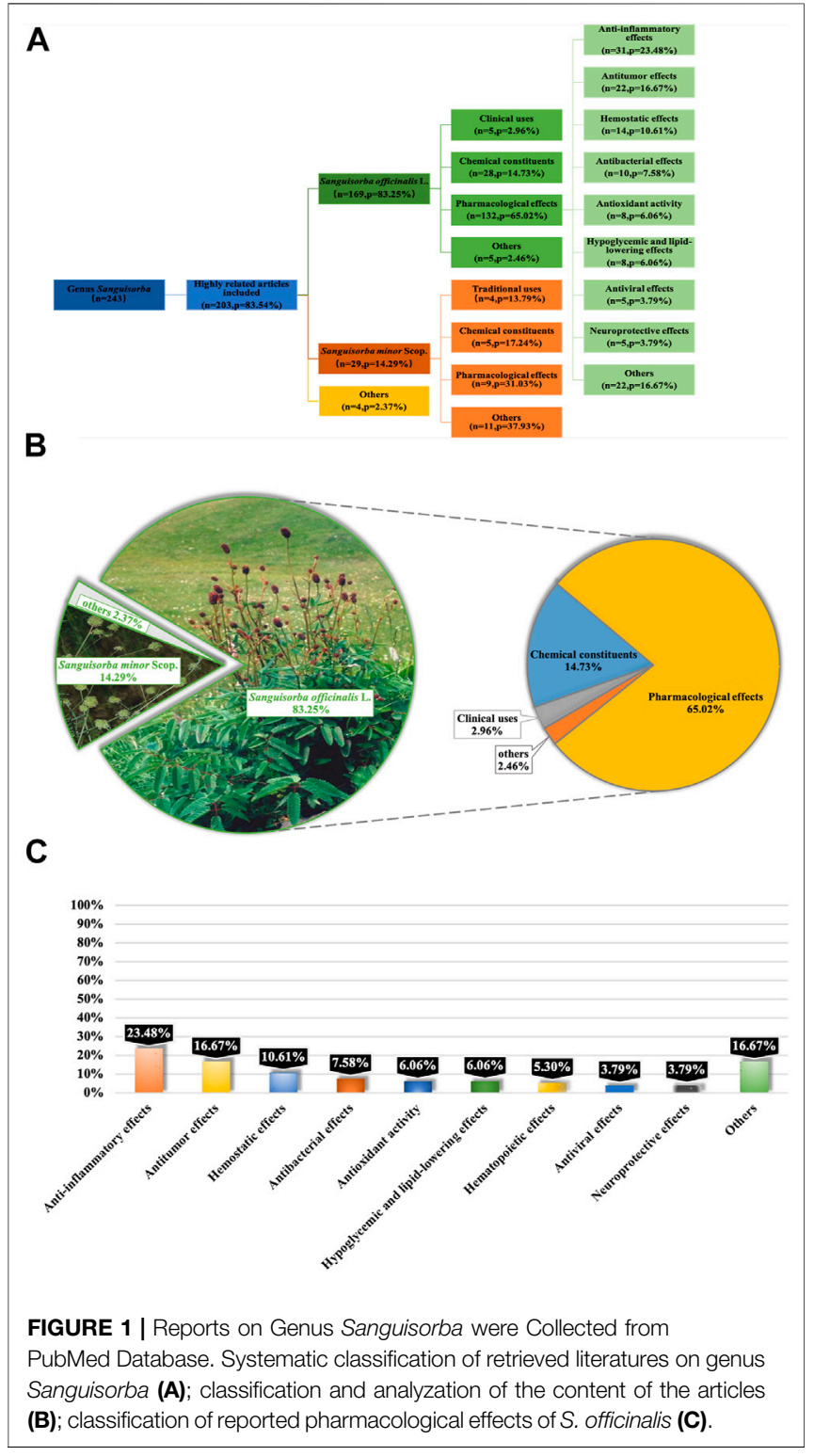

The genus Sanguisorba is a member of the Rosaceae family, and the Rosaceae plants have a certain common leaf intergrowth, often accompanied by leaf stipules. The petals are mostly bisexual, and unisexual is relatively rare. The Plant List (The Plant List, 2021), International Plant Name Index (International Plant Name Index, 2021) and Kew Botanical Garden (Kew Botanical Garden, 2021a; Kew Botanical Garden, 2021b) were used for obtaining the scientific names and information on the subspecies and cultivars. Studies have demonstrated that the crude extracts from plants belonging to genus Sanguisorba or the purified monomers isolated from the plants of this genus exhibit various pharmacological activities, including anti-inflammatory (Su et al., 2018a; Guo et al., 2019; Yasueda et al., 2020), anticancer (Liu et al., 2016; Nam et al., 2017; Tan et al., 2019; Bai et al., 2020a; Liao et al., 2020), anti-lipid peroxidation (Zhang et al., 2012a; Romojaro et al., 2013a; Kim et al., 2018a; Lenzi et al., 2019), anti-bacteria (Su et al., 2019; Zhu et al., 2020a), antidiabetes (Kuang et al., 2011; Son et al., 2015), hepatoprotective (Stojiljković et al., 2019; Meng et al., 2020), and anti-obesity (Jung et al., 2016; Im et al., 2017; Ji et al., 2018) properties, both in vitro and in vivo (Figure1).

S. officinalis, also referred to as $\mathrm{Zi}-\mathrm{Yu}$ in South Korea and Japan, Di-Yu in China, and Burnet in the Western nations, has been used as a traditional medicine for a long time (Nguyen et al., 2008). It is used widely in Asia for the treatment of inflammatory and metabolic diseases including diarrhea, chronic intestinal infections, duodenal ulcers, bleeding and diabetes (Zhang et al., 2012b; Seo et al., 2016; Zhang et al., 2018). The pharmacological activity of Sanguisorba has been receiving increasing attention from scholars in recent years.

The other species of genus Sanguisorba are also being studied by researchers worldwide. One among these species is $S$. minor, which is an edible perennial herb belonging to family Rosaceae, distributed widely across the Sinai Peninsula of Egypt and the temperate regions of Europe, particularly the Mediterranean regions such as Italy (Ceccanti et al., 2019). S. minor, as an edible wild plant, is a common ingredient of the Mediterranean diet, and its young shoots and leaves are often mixed with traditional vegetables and consumed as a salad (Romojaro et al., 2013b; Guarrera and Savo, 2016; Karkanis et al., 2019) $S$. minor contains polyphenols in huge amounts and, therefore, has great antioxidant, anti-tumor and antibacterial properties (Ceccanti et al., 2019; Lenzi et al., 2019; Finimundy et al., 2020).

While $S$. officinalis and $S$. minor are the most widespread of all Sanguisorba species, there are also other species in this genus that exhibit different pharmacological effects. So far, over 270 chemical constituents have been identified in the plants of genus Sanguisorba, including flavonoids, triterpenoids, 
steroids, lignans, and organic acids, etc., (Zhao et al., 2017; Jang et al., 2018a).

Reports on genus Sanguisorba available in the current literature were collected from Google Scholar, Web of Science and PubMed. The deadline for the literature selected was up to December 2020. We analyzed articles related to not only the species of genus Sanguisorba (Figure1A), but also the other two major species of S. officinalis and S. minor (Figures 1B,C).

The aim of the present report is to review the research advances concerning genus Sanguisorba, in terms of its chemical composition, pharmacological activity, toxicology and clinical application, to assist in future drug development and applications involving this species.

\section{THE BOTANICAL DESCRIPTION AND DISTRIBUTION OF GENUS SANGUISORBA}

Genus Sanguisorba comprises perennial flowering herbs belonging to family Rosaceae and includes about 148 species and subspecies distributed mainly across East Asia and southern Europe (Zhu et al., 2019). Figure 2 shows that the specific distribution of genus Sanguisorba used for medicinal purposes is cultivated mainly in East Asia, although its cultivation in Europe is also increasing lately. S. officinalis and S. minor are the most widespread species of genus Sanguisorba, and their botanical, biological, and ecological characteristics are discussed in the sections ahead.

\section{Sanguisorba officinalis $\mathbf{L}$.}

S. officinalis (Figures 3A-C), which is referred to as $\mathrm{Zi}-\mathrm{Yu}$ in South Korea and Japan, Di-Yu in China, and Burnet in the western nations, is a perennial plant distributed across a range of geographical regions, including the wet grasslands, hillside meadows, and pastures of the colder regions of Europe and Asia and the northern regions of North America (Bączek, 2015; Zhu et al., 2019). The plants of this species have a height in the range of $30-120 \mathrm{~cm}$ and upright stems. Their roots are sturdy and mostly spindleshaped, while the leaves are pinnate with serrated margins. The flowers are dark red and grow in dense clusters or spikes at the length of 1-7 cm (Bunse et al., 2020). The flowering and fruiting period in this species ranges from July to October mostly (Yang et al., 2015). Pawlaczyk-Graja et al. (2016) believed that the plants of this species exude the scent of cucumber. The seeds of this species have the optimal germination temperature and requirements similar to those of all the other species within genus Sanguisorba, although. The seeds of $S$. officinalis germinate more easily than those of the other species under the same conditions, which indicates that this species is better adapted to extreme temperature conditions, which might also be one of the reasons for its wide distribution (Holloway and Matheke, 2003).

Sanguisorbae Radix (Figure 3D), which is the dried root of Sanguisorba officinalis L. or Sanguisorba officinalis var. longifolia (Bertol.) T.T.Yu and C.L.Li (S. longifolia Bertol) according to the documentation in Chinese Pharmacopoeia, has been used as Traditional Chinese Medicine (TCM). The plants are uprooted and collected immediately after germination in spring or after withering in autumn. After washing the plants, the fibrous roots are discarded and the remaining plant is whole-dried or slice-dried for later use in TCM. Similar documentation is available in the Polish Pharmacopoeia, according to which the underground parts of plants (rhizomes and roots) are known for their healing properties (Bączek, 2015).

\section{Sanguisorba minor Scop.}

Sanguisorba minor Scop. (also referred to as small or salad burnet) is a drought-tolerant species that exhibits extremely high drought resistance (Fry et al., 2018). The plants of this species are approximately $60-105 \mathrm{~cm}$ in height and are distributed widely across the Sinai Peninsula, Egypt and temperate regions of Europe (Ceccanti et al., 2019).

S. minor (Figure 4) comprises edible perennial herbs having pinnate leaves, red-green petals (Cuccioloni et al., 2012), short petioles, and $1-1.5 \mathrm{~cm}$ long leaflets growing in pairs or alternately. Inflorescences appear at the end of plant stems. The flowers of this species have four sepals and no petals, with a long peduncle flower head that is globose or ellipsoid and up to $2 \mathrm{~cm}$ in length (Paniagua-Zambrana et al., 2020).

\section{TRADITIONAL USES OF GENUS SANGUISORBA PLANTS}

Historical documents state S. officinalis, S. minor and Sanguisorba albanica András. and Jáv. (S. albanica) as traditional foods because of their attractive flavor (Caporaso et al., 2015; Lenzi et al., 2019). The plants of these species were added to cheese, butter, ice drink, fresh orange juice, Kiwi juice, and vinegar for flavor enhancement (Sanchez-Bel et al., 2015; Sabbatini et al., 2019). Fresh leaves from young plants are used as a seasoning for salads and meat dishes in certain western nations (Bączek, 2015). In China, S. officinalis is regarded as an important tonic food and is frequently added to dishes as such as Diyu porridge, Diyu chitterlings soup, Diyu Huaihua Yin and Shaguo Diyu (Zhao et al., 2017) to diversify the flavors in modern diets.

In addition to being a wild edible plants, S. officinalis is also widely used for treating several diseases. Sanguisorbae Radix, the dry root of S. officinalis or S. longifolia Bertol, has been traditionally used for cooling the blood, clearing heat, healing wounds and alleviating snake bites (Hachiya et al., 2001; Karkanis et al., 2014; Liu et al., 2014; Jang et al., 2018b). In Korea, the whole plant of S. officinalis is used slightly differently compared to its roots; while the whole plant is commonly applied for the treatment of diseases in women and bloody stool hemorrhoid pus, the root is mostly used for treating inflammation and for skin regeneration (Kim and Song, 2011). In the Armenian region, the aerial part of S. officinalis has been in use as a traditional medicine for treating different diseases (Ginovyan et al., 2020). Studies reported in recent years have provided scientific evidence that the components present in the different parts of S. officinalis plant are 

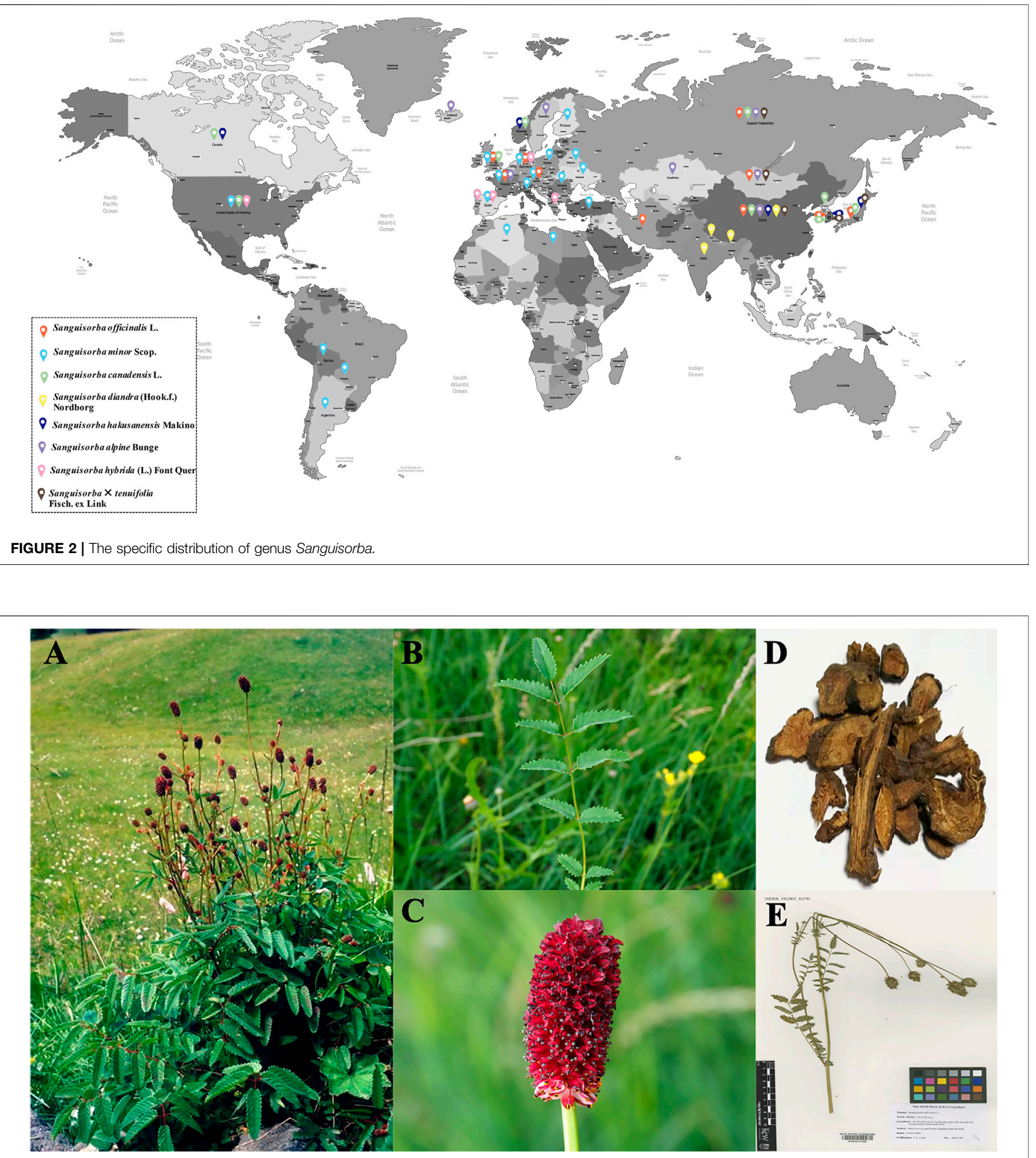

FIGURE $\mathbf{3}$ | Sanguisorba officinalis L. Plants (Kew Botanical Garden, 2021a). The whole plant of S. officinalis (A); the leaves of S. officinalis (B); the flower of S. officinalis (C); Sanguisorbae Radix (D); specimen of S. officinalis (E).

indeed different (Na et al., 2019). It is reported that the aerial parts of S. officinalis contain higher amount of polyphenols compared to its roots (Bunse et al., 2020).
S. minor has several similarities with S. officinalis, such as both are wild edible species that have also been used in traditional medicine in different regions. Owing to its constituent bioactive 


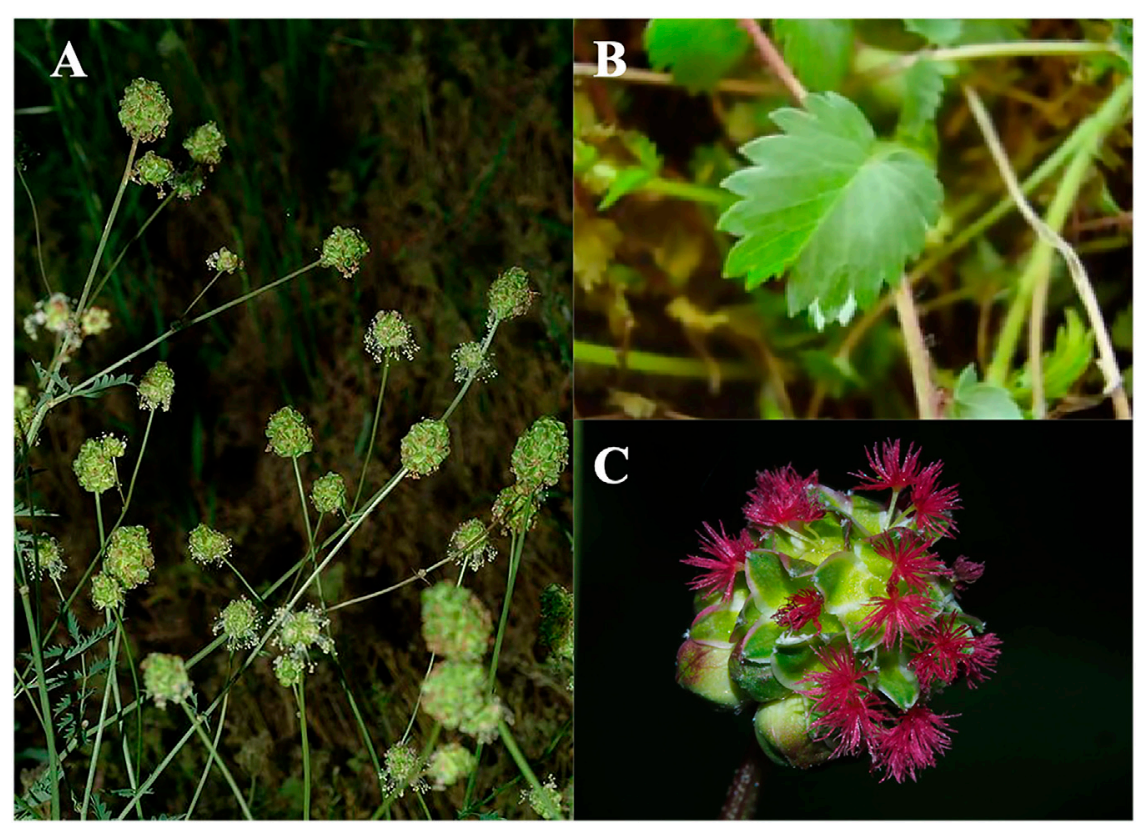

FIGURE 4 | Sanguisorba minor Scop. Plants (Kew Botanical Garden, 2021 b). The whole plant of S. minor (A); the leaves of S. minor (B); the flowers of S. minor (C).

compounds, minerals and fiber, S. minor is added to omelets and scrambled eggs in the traditional Mediterranean cuisine (Romojaro et al., 2013a). It is also mixed with the common vegetables as a delicacy in Italian cuisine (Guarrera and Savo, 2016).

\section{CHEMICAL CONSTITUENTS IN THE PLANTS BELONGING TO GENUS SANGUISORBA}

The present report summarizes the research findings reported in the research papers and articles on the chemical component separation and identification of genus Sanguisorba plants, published between the years 2008 and 2020 (Table 1), based on, but not limited, to the summary of Zhao et al. (2017), which includes the studies published mainly between the years 2008 and 2014. So far, five species and varieties of this genus have been studied phytochemically, and over 270 compounds have been identified, including flavonoids, triterpenes, phenols, terpenes, fatty acids, and several other types as sterols and neolignans. According to the preliminary pharmacological studies, the extracts and compounds isolated from the plants of this genus exhibit a wide range of biological activities.

\section{PHARMACOLOGICAL EFFECTS EXHIBITED BY GENUS SANGUISORBA}

Many researchers have reported a variety of pharmacological effects of genus Sanguisorba, not only in vitro, but also a large amount of in vivo experimental data, involving antiinflammatory, anti-cancer, anti-lipid peroxidation, antibacteria, anti-diabetes, hepatoprotective, and anti-obesity effects.

\section{Anti-Inflammatory Effects}

$S$. officinalis has been used for the treatment of inflammatory diseases, including the airway inflammation in bronchial asthma (Lee et al., 2010), contact dermatitis (Jo et al., 2015), specific dermatitis (Park et al., 2015; Yang et al., 2016a), nephritis (Zhao et al., 2019), colitis (Shao et al., 2017; Fang et al., 2018; Yasueda et al., 2020), etc., for a long time.

Yu et al. (2011) reported that the ethanol extract of S. officinalis plants could block the production of representative inflammatory mediators nitric oxide (NO) and prostaglandin E2 (PEG2) at the transcription level in an in vitro model of RAW264.7 cells stimulated by $1 \mu \mathrm{g} / \mathrm{ml}$ lipopolysaccharide (LPS). In 2015, Yang et al. reported that the ethanol extract of $S$. officinalis plants could inhibit the production of pro-inflammatory chemokines in human keratinocytes $(\mathrm{HaCaT})$ cells induced by tumor necrosis factor (TNF)- $\alpha$ /interferon (IFN)- $\gamma$; these cytokines are signal peptides involved in several inflammatory skin diseases. In the following year, the authors reported that the water extract of these plants exhibited the same anti-inflammatory effect in bone marrow-derived mast cells and $\mathrm{HaCaT}$ cells, demonstrating that the degranulation of immuno-globulin $\mathrm{E}$ ( $\mathrm{IgE}$ )/antigen (Ag)-activated mast cells, phosphorylation of p38, and JNK in $\mathrm{HaCaT}$ cells were inhibited (Yang et al., 2016b). Seo et al. further confirmed the anti-inflammatory effect of the water extract of $S$. officinalis (HSO) in an in vivo mouse model induced by LPS $(3 \mathrm{mg} / \mathrm{kg}$ ), demonstrating that the oral consumption of HSO (5 or $25 \mathrm{mg} / \mathrm{kg}$.day) significantly reduced the levels of serum as well as 
TABLE 1 | Chemical constituents in the genus Sanguisorba (2008-2020).

\begin{tabular}{|c|c|c|c|c|c|}
\hline No. & Name & Classification & Plant sources & $\begin{array}{l}\text { Extraction solvent } \\
\text { andparts }\end{array}$ & References \\
\hline \multicolumn{6}{|c|}{ Triterpenes } \\
\hline 1 & Changyediyuine I & triterpenes & S. Iongifolia Bertol & 95\% EtOH extract of powdered dried roots & Shen et al. (2008) \\
\hline 2 & Changyediyuine II & triterpenes & S. Iongifolia Bertol & 95\% EtOH extract of powdered dried roots & Shen et al. (2008) \\
\hline 3 & Changyediyuine III & triterpenes & S. Iongifolia Bertol & 95\% EtOH extract of powdered dried roots & Shen et al. (2008) \\
\hline 4 & arjunic acid & triterpenes (oleanane) & S. officinal & ethanol extract of roots & Ponou et al. (2011) \\
\hline 5 & 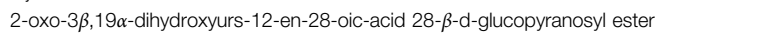 & triterpenes & S. tenuifolia & $70 \%$ EtOH extract of dried roots & Kuang et al. (2011) \\
\hline 6 & $2 \alpha, 19 \alpha$-dihydroxy-3-oxo-12-ursen-28-oic acid $\beta$-D-glucopyranosyl ester & triterpenes & S. tenuifolia & $70 \%$ EtOH extract of dried roots & Kuang et al. (2011) \\
\hline 7 & $2 \alpha, 3 \alpha, 9 \alpha, 24$-tetrahydroxyolean-12-en-28-oic acid & triterpenes (ursane) & S. officinal & $75 \%$ ethanol extract of the dried and powdered stems and roots & Wang et al. (2014) \\
\hline 8 & $1 \alpha, 2 \beta, 3 \beta, 19 \alpha$-tretrahydroxyurs-12-en-28-oic acid & triterpenes (ursane) & S. officinal & $70-80 \%$ EtOAc/hexanes extract of the roots & Eyong et al. (2017) \\
\hline 9 & 3-oxo-15 $\alpha, 19 \alpha$-dihydroxyurs-12-en-28-oic acid & triterpenes (ursane) & S. officinal & ethanol extract of roots & Wang et al. (2019a) \\
\hline 10 & 3-oxo-7 $\beta, 19 \alpha$-dihydroxyurs-12-en-28-oic acid & triterpenes (ursane) & S. officinal & ethanol extract of roots & Wang et al. (2019a) \\
\hline 11 & 18,19-seco, $1 \beta$-hydroxyl-3,19-dioxo-urs-11,13 (18)-dien-28-oic acid & triterpenes (ursane) & S. officinal & ethanol extract of roots & Wang et al. (2019a) \\
\hline 12 & $1 \beta$-hydroxyeuscaphic acid & triterpenes (ursane) & S. officinal & ethanol extract of roots & Wang et al. (2019a) \\
\hline 13 & $19 \alpha$-hydroxy ursolic acid & triterpenes (ursane) & S. officinal & ethanol extract of roots & Wang et al. (2019a) \\
\hline 14 & ursolic acid & triterpenes (ursane) & S. officinal & ethanol extract of roots & Wang et al. (2019a) \\
\hline 15 & 3-oxo-urs-11,13 (18)-dien-19,28-olide & triterpenes (ursane) & S. officinal & ethanol extract of roots & Wang et al. (2019b) \\
\hline 16 & 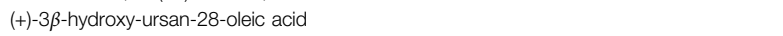 & triterpenes & S. officinal & $\mathrm{MeOH} / \mathrm{H}_{2} \mathrm{O}$ and $\mathrm{EtOH} / \mathrm{H}_{2} \mathrm{O}$ extract of fresh flowers & Bunse et al. (2020) \\
\hline 17 & 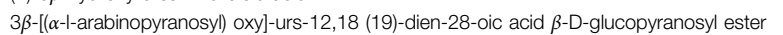 & triterpenes & S. officinal & $\mathrm{MeOH} / \mathrm{H}_{2} \mathrm{O}$ and $\mathrm{EtOH} / \mathrm{H}_{2} \mathrm{O}$ extract of fresh flowers & Bunse et al. (2020) \\
\hline 18 & 2,19 $\alpha$-dihydroxy-3-oxours-1,12-dien-28-oic acid 28-O- $\beta$-D-glucopyranosyl ester & triterpenes (ursane) & S. officinal & $95 \%$ EtOH extract of the dried roots & Wang et al. (2020b) \\
\hline 19 & 3 $\alpha, 19 \alpha, 24$-trihydroxyolean-12-en-28-oic acid & triterpenes (oleanane) & S. officinal & $95 \%$ EtOH extract of the dried roots & Wang et al. (2020b) \\
\hline 20 & 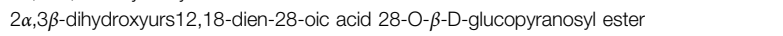 & triterpenes (ursane) & S. officinal & $95 \%$ EtOH extract of the dried roots & Wang et al. (2020b) \\
\hline 21 & 7-dimethyl-8-hydroxyoctadien-1-ol & triterpenes & S. officinal & $95 \%$ EtOH extract of the dried roots & Wang et al. (2020b) \\
\hline \multicolumn{6}{|c|}{ Phenols } \\
\hline 22 & methyl 4-O- $\beta$-D-glucopyranosy-5-hydroxy-3-methoxylbenzoate & phenols & S. officinal & $70 \%$ EtOH extract of the air-dried roots & Zhang J. et al. (2012) \\
\hline 23 & 3,3', $4^{\prime}$-tri-O-methylellagic acid & phenols & S. officinal & $70 \%$ EtOH extract of the air-dried roots & Zhang J. et al. (2012) \\
\hline 24 & 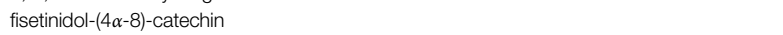 & phenols & S. officinal & $70 \%$ EtOH extract of the air-dried roots & Zhang J. et al. (2012) \\
\hline 25 & $\alpha$-resorcylic & phenolic acids & S. officinal & $80 \%$ methanol extract of air-dried rhizomes and herbaceous tissues & Biernasiuk et al. (2015) \\
\hline 26 & $\beta$-resorcylic & phenolic acids & S. officinal & $80 \%$ methanol extract of air-dried rhizomes and herbaceous tissues & Biernasiuk et al. (2015) \\
\hline 27 & protocatechuic & phenolic acids & S. officinal & $80 \%$ methanol extract of air-dried rhizomes and herbaceous tissues & Biernasiuk et al. (2015) \\
\hline 28 & gentisie & phenolic acids & S. officinal & $80 \%$ methanol extract of air-dried rhizomes and herbaceous tissues & Biernasiuk et al. (2015) \\
\hline 29 & p-hydroxyphenylacetic & phenolic acids & S. officinal & $80 \%$ methanol extract of air-dried rhizomes and herbaceous tissues & Biernasiuk et al. (2015) \\
\hline 30 & p-coumaric $(E+Z)$ & phenolic acids & S. officinal & $80 \%$ methanol extract of air-dried rhizomes and herbaceous tissues & Biernasiuk et al. (2015) \\
\hline 31 & syringic & phenolic acids & S. officinal & $80 \%$ methanol extract of air-dried rhizomes and herbaceous tissues & Biernasiuk et al. (2015) \\
\hline 32 & vanillic & phenolic acids & S. officinal & $80 \%$ methanol extract of air-dried rhizomes and herbaceous tissues & Biernasiuk et al. (2015) \\
\hline 33 & sinapic $(E+Z)$ & phenolic acids & S. officinal & $80 \%$ methanol extract of air-dried rhizomes and herbaceous tissues & Biernasiuk et al. (2015) \\
\hline 34 & (-)-epigallocatechin & phenols & S. officinal & methanol extract of air-dry raw material & Bączek, (2015) \\
\hline 35 & (-)-epicatechin & phenols & S. officinal & methanol extract of air-dry raw material & Bączek, (2015) \\
\hline 37 & (-)-epigallocatechin gallate & phenols & S. officinal & methanol extract of air-dry raw material & Bączek, (2015) \\
\hline 38 & $(-)$-epicatechin gallate & phenols & S. officinal & methanol extract of air-dry raw material & Bączek, (2015) \\
\hline 39 & astragalin & phenols & S. officinal & methanol extract of air-dry raw material & Bączek, (2015) \\
\hline 40 & apigenin-O-deoxyhexoside & phenols & S. minor & n.d. & Guarrera and Savo, $(2016$ \\
\hline 41 & quercetin-galloyl-hexoside & phenols & S. minor & lyophilized young leaves and stems were added to the vegetable oils & Romojaro et al. (2018) \\
\hline 45 & taxifolin 3-O- $\beta$-D-glucopyranoside & phenols & S. officinal & $\mathrm{MeOH}$ extract of the dried crushed roots & Su et al. (2018a) \\
\hline 46 & methyl 3-(3-D-glucopyranosyloxy)-4-hydroxy-5-methoxybenzoate. & phenols & S. officinal & methanol and Aqueous extract of the roots & Su et al. (2018b) \\
\hline 47 & methyl 4-( $\beta$-D-glucopyranosyloxy)-3-hydroxy-5-methoxybenzoate & phenols & S. officinal & $\mathrm{MeOH}, \mathrm{EtOAc}, \mathrm{n}-\mathrm{BuOH}$ and water extracts & Su et al. (2019) \\
\hline 48 & apigenin derivatives & phenols & S. minor & $80 \%$ methanol extract of aerial parts and roots & Karkanis et al. (2019) \\
\hline 49 & chlorogenic & phenols & S. minor & $80 \%$ methanol extract of aerial parts and roots & Karkanis et al. (2019) \\
\hline 50 & caffei & phenols & S. minor & $80 \%$ methanol extract of aerial parts and roots & Karkanis et al. (2019) \\
\hline 51 & chicoric acid derivatives & phenols & S. minor & $80 \%$ methanol extract of aerial parts and roots & Karkanis et al. (2019) \\
\hline 52 & pedunculagin & phenols & S. minor & $80 \%$ methanol extract of aerial parts and roots & Karkanis et al. (2019) \\
\hline 53 & B-type(epi)catechin tetramer & phenols & S. minor & $80 \%$ methanol extract of aerial parts and roots & Karkanis et al. (2019) \\
\hline 54 & sanguiin $\mathrm{H}-10$ isomer 1 & phenols & S. minor & $80 \%$ methanol extract of aerial parts and roots & Karkanis et al. (2019) \\
\hline
\end{tabular}


TABLE 1 | (Continued) Chemical constituents in the genus Sanguisorba (2008-2020).

\section{punicalagin gallate}

lambertianin $\mathrm{C}$
sanguiin $\mathrm{H}-10$ isomer 2

galloyl-bis-HHDP- glucoside

\section{ellagic acid hexoside}

gallic acid glycosid

digalloyl hexoside

brevifolin-carboxylic acid isomers

trigalloyl-hexoside

methoxy trihydroxybenzoic acid methyl ester-O-sulfate

ellagic acid-pentose

ethyl gallate

galloyl-ellagic acid

methyl-ellagic acid-pentose

3,3'-O-dimethyl ellagic acid-sulfate

methoxy trihydroxybenzoic acid methyl ester-O-sulfate

3,4'-O-dimethyl ellagic acid

$3,3^{\prime}, 4^{\prime}$-O-trimethyl ellagic acid

cyanidin-galloyl-hexose

cyanidin-malonyl-glucose

$\beta$-hydroxypro-piovanillone
methyl 3-O-methyl-gallate

methyl 3-O-methyl-gallate
chavicol $4-O-\alpha-L$-arabinofuranosyl- (1 $\rightarrow 6)-\beta$-D-glucopyranoside

2-di-O-galloyl- $\beta$-D-glucopyranoside

sanguisorbaside $A$

sanguisorbaside $B$

phenols

phenols

phenols

phenols

phenols

phenolic acids

phenolic acids

phenolic acids

phenolic acids

phenolic acids

phenolic acids

phenolic acids
phenolic acids

phenolic acids

phenolic acids

phenolic acids

phenolic acids

phenolic acids

phenols

phenols

phenols

phenols

phenols

phenols

phenolic glycosides

phenolic glycosides

S. minor

S. minor

S. minor

S. minor

S. Obtusa
S. officinal

S. officinal

S. officinal

S. officinal

S. officinal

S. officinal

S. officinal

S. officinal

S. officinal

S. officinal

S. officinal

S. Officinal

S. officinal

s. officinal

S. officinal

S. officinal

S. officinal

S. officinal

S. officinal

S. officinal

S. officinal

$80 \%$ methanol extract of aerial parts and roots

$80 \%$ methanol extract of aerial parts and roots $\quad$ Karkanis et al. (2019)

$80 \%$ methanol extract of aerial parts and roots Karkanis et al. (2019)

$80 \%$ methanol extract of aerial parts and roots Karkanis et al. (2019)

70\% ethanol extract of dried powder Zhu et al. (2019)

$70 \%$ ethanol extract of dried powder

$70 \%$ ethanol extract of dried powder

$70 \%$ ethanol extract of dried powder

$70 \%$ ethanol extract of dried powder

$70 \%$ ethanol extract of dried powder

$70 \%$ ethanol extract of dried powder

$70 \%$ ethanol extract of dried powder

$70 \%$ ethanol extract of dried powder

$70 \%$ ethanol extract of dried powder

$70 \%$ ethanol extract of dried powder

$70 \%$ ethanol extract of dried powder

$70 \%$ ethanol extract of dried powder

$\mathrm{MeOH} / \mathrm{H}_{2} \mathrm{O}$ and $\mathrm{EtOH} / \mathrm{H}_{2} \mathrm{O}$ extract of fresh flowers

$\mathrm{MeOH} / \mathrm{H}_{2} \mathrm{O}$ and $\mathrm{EtOH} / \mathrm{H}_{2} \mathrm{O}$ extract of fresh flowers

$95 \% \mathrm{EtOH}$ extract of the dried roots

$95 \%$ ElOH extract of the dried roots

$95 \%$ EIOH extract or the dined roots

$95 \%$ EtOH extract of the dried roots

Zhu et al. (2019)

Zhu et al. (2019)

Zhu et al. (2019)

Zhu et al. (2019)

Zhu et al. (2019)

Zhu et al. (2019)

Zhu et al. (2019)

Zhu et al. (2019)

Zhu e t. (2019)

Zhu et al (2019)

Zhu et al. (2019)

Bunse et al. (2020)

Bunse et al. (2020)

Wang et al. (2020a)

Wang et al. (2020a)

Wang et al. (2020a)

Wang et al (2020a)

Wang et al. (2020a)

Favonoids

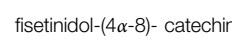

quercetin

epicatechin-(4 $\rightarrow 8$ )-gallocat- echin

taxifolin-7-O- $\beta$-D- glucopyranoside

gallocatechin

isorhamnetin hexoside III

taxifolin

isorhamnetin-sulfate

isorhamnetin

swertianolin

baicalin

okanin

(2R,3R)-(+)-dihydrokaempferol-3- $\beta$-D-glucopyranoside

maesopsin-6-O-glucopyranoside

$(-)$-gallocatechin

taxifolin 3-O-glucoside

flavonoids S. officinal

flavonoids

flavonoids

flavonoids

flavonoids

flavonoids

flavonoids

flavonoids

flavonoids

flavonoids

flavonoids

flavonoids

flavonoids
flavonoids

flavonoids

flavonoids

flavonoids

flavonoids
S. officinal

S. officinal
S. officinal

S. officinal
S. officinal

S. officinal

S. officinal

S. officinal

S. officinal

S. officinal

S. officinal

S. officinal

S. officinal

S. officinal

S. officinal

S. officinal

S. officinal

S. officinal
$70 \% \mathrm{EtOH}$ extract of the air-dried roots

$70 \%$ ethanol extract of the dried powder

$70 \%$ ethanol extract of the dried powder

$70 \%$ ethanol extract of the dried powder

$70 \%$ ethanol extract of the dried powder

$70 \%$ ethanol extract of the dried powder

$70 \%$ ethanol extract of the dried powder

$70 \%$ ethanol extract of the dried powder

$70 \%$ ethanol extract of the dried powder

$70 \%$ ethanol extract of the dried powder

$70 \%$ ethanol extract of the dried powder

$95 \% \mathrm{EtOH}$ extract of the dried roots

$95 \% \mathrm{EtOH}$ extract of the dried roots

$95 \% \mathrm{EtOH}$ extract of the dried roots

$95 \% \mathrm{EtOH}$ extract of the dried roots
$70 \%$ ethanol extract of the dried powder
Zhang S. et al. (2012)

Zhu et al. (2019)

Zhu et al. (2019)

Zhu et al. (2019)

Zhu et al. (2019)

Zhu et al. (2019)

Zhu et al. (2019)

Zhu et al. (2019)

Zhu et al. (2019)

Zhu et al. (2019)

Wang et al. (2020b

Wang et al (2020)

Wang a

Wang et al. (2020b)

\section{Other compounds}

98 (7S,8R)-4,9,5', ' $^{\prime}$-tetrahydroxy-3,3'-dimethoxy-8-O-4'-neolignan-7-O- $\alpha$--rhamnopyranosid

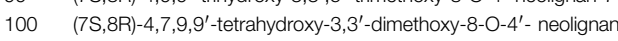

101 9-O-[6-O-acetyl- $\beta$-d-glucopyranosyl]-4-hydroxycinnamic acid

102 8-O- $\beta$-d-glucopyranosyl-(R)-(+)-3,4,8-trihydroxy methyl phenylpropionate 3 -sitosterol neolignans stero phenylpropanoid glycosidss
S. officinal

S. officinal

S. officinal

S. officinal
$80 \% \mathrm{EtOH}$ extract of the roots

$80 \%$ EtOH extract of the roots

$80 \% \mathrm{EtOH}$ extract of the roots

$80 \%$ EtOH extract of the roots

$80 \%$ chloroform-methanol extract of the herb and underground organs
Hu et al. (2012)

Huet al. (2012)

Hu et al. (2012)

Hu et al. (2012) 
TABLE 1 | (Continued) Chemical constituents in the genus Sanguisorba (2008-2020).

$\beta$-sitosterol D-glucoside

105 campesterol

stigmasterol

rosamultin

kajiichigoside $\mathrm{F} 1$

(+)-5-methoxyl-cycloolivil

1 (+)-5,5'-dimethoxyl-cycloolivil

112 (2E)-7-hydroxy-3,7-dimethyl-2-octenyl 6-O- $\alpha$-L-arabinofuranosyl- $\beta$-D-glucopyranoside

(2E-3,7-dimethyl-2,6-octadien-1-yl 6-O- $\alpha$-L-arabinofuranosyl- $\beta$-D-glucopyranoside

7-hydroxy-3,7-dimethyloctyl-6-O- $\alpha$-L-arabinofuranosyl- $\beta$-D-glucopyranoside

115 (2E-7-hydroxy-3,7-dimethyl-2-octenyl 6-O- $\alpha$-L-arabinofuranosyl- $\beta$-D-glucopyranoside

116 (2E)-7-hydroxy-3,7-dimethyl-2-octenyl 6-O- $\alpha$-L-arabinopyranosyl- $\beta$-D-glucopyranoside

117 (2E,6Z)-3,7-dimethyl-8-hydroxyoctadien-1-ol

118 8-hydroxygeraniol-1-O-(6-O-galloy)- $\beta$-D-glucopyranoside

119 8-hydroxygeraniol-1-O- $\alpha-$-larabinofuranosyl-( $1 \rightarrow 6)-\beta$-D-glucopyranoside

20 ethyl isobutyrate hexanal

(Z)-4-heptenalb octanal

(Z)-3-hexenol linalool oxide

124 (Z)-3-hexenol nonanal

125 linalool

126 (E,Z)-2,6-nonadienal $\alpha$-terpineol

127 verbenone

128 (E)-2-nonenal linalool

129 ethyl isobutyrate (Z)-3-hexenallb

130 (E,Z)-2,6-nonadienal ethyl isobutyrate (Z)-4-heptenallby

131 (E,Z)-2,6-nonadiena

132 octanal rose oxide

133 (E,Z)-2,6-nonad

$135 \alpha$-linolenic acid

136 palmitic

137 linoleic acid

138 stearic

140 lauric

141 eicosatrie-noic acid

142 dihomo- $\gamma$-linolenic

143 behenic acids

144 2-phenylethylamine

$145 \quad \beta$-L-arabinofuranoside

$146 \mathrm{n}$-butyl- $\beta$-D-fructofuranoside

147 lyoniside

n.d, no data. stero

stero

stero

sterol

saponins
saponins

aryl-tetralin-type lignans

any-tetralin-type lignans

monoterpenoid glycosides

monoterpenoid glycosides

monoterpenoid glycosides

monoterpenoid glycosides

monoterpenoid glycosides

monoterpenoid glycosides

monoterpenoid glycosides

monoterpenoid glycosides

essential oils

essential oils

essential oils

essential oils

essential oils

essential oils

essential oils

terpenoids

essential oils

essential oils

essential oils

essential oils
essential oils

essential oils
essential oils

essential oils

fatty acid

fatty acid

fatty acid

fatty acid

fatty acid
fatty acid

fatty acid

fatty acid
fatty acid

fatty acid

fatty acid

amine

gycosides

glycosid
lignan
S. officinal

S. officinal
S. officinal

S. officinal
S. officinal

S. officinal

S. officinal

S. officinal

S. officinal

S. officinal

S. officinal

S. officinal

S. officinal

S. officinal

S. officinal

S. officinal

S. albanica

S. albanica

S. albanica

S. albanica

S. albanica

S. albanica

S. albanica

S. albanica

S. albanica

S. albanica

S. albanica

S. albanica

S. albanica

S. albanica

S. albanica

S. minor

S. minor

S. minor

S. minor

S. minor

S. minor

S. minor

S. minor

S. minor

S. Afficina

S. officinal

S. Officinal

S. officinal
$80 \%$ chloroform-methanol extract of the herb and underground organs

$80 \%$ chloroform-methanol extract of the herb and underground organs

$80 \%$ chloroform-methanol extract of the herb and underground organs

$\mathrm{MeOH}$ extract of the dried crushed roots

$70 \%$ EtOH extract of the whole plants

$70 \% \mathrm{EtOH}$ extract of the whole plants

$\mathrm{MeOH}$ extract of the dried crushed roots

$\mathrm{MeOH}$ extract of the dried crushed roots

methanol and aqueous extract of the roots

methanol and aqueous extract of the roots

$70 \% \mathrm{EtOH}$ extract of the air-dried and powdered

$70 \% \mathrm{EtOH}$ extract of the air-dried and powdered

stems, leaves, and flowers in Thymol

stems, leaves, and flowers in Thymo

stems, leaves, and flowers in Thymo

stems, leaves, and flowers in Thymo

stems, leaves, and flowers in Thymo

stems, leaves, and flowers in Thyma

stems, leaves, and flowers in Thymo

stems, leaves, and flowers in Thymo

stems, leaves, and flowers in Thymo

stems, leaves, and flowers in Thyma

stems, leaves, and flowers in Thymo

stems, leaves, and flowers in Thymo

stems, leaves, and flowers in Thymo

stems, leaves, and flowers in Thymo

stems, leaves, and flowers in Thymo

$80 \%$ methanol extract of leaves, stems and roots

$80 \%$ methanol extract of leaves, stems and roots

$80 \%$ methanol extract of leaves, stems and roots

$80 \%$ methanol extract of leaves, stems and roots

$80 \%$ methanol extract of leaves, stems and roots

$80 \%$ methanol extract of leaves, stems and roots

$80 \%$ methanol extract of leaves, stems and roots

$80 \%$ methanol extract of leaves, stems and roots

$80 \%$ methanol extract of leaves, stems and roots

$\mathrm{MeOH} / \mathrm{H}_{2} \mathrm{O}$ and $\mathrm{EtOH} / \mathrm{H}_{2} \mathrm{O}$ extract of fresh flowers

$95 \% \mathrm{EtOH}$ extract of the dried roots

$95 \% \mathrm{EtOH}$ extract of the dried roots

$95 \% \mathrm{EtOH}$ extract of the dried roots
Mirgos et al. (2012

Mirgos et al. (2012)

Mirgos et al. (2012)

Mirgos et al. (2012)

Su et al. (2018a)

Su et al. (2018a)
Wang et al. (2018)

Wang et al. (2018)

Su et al. (2018a)

Su et al. (2018b)

Su et al. (2018b)

Su et al. (2018b)

Su et al. (2018b)

Guo et al. (2019)

Guo et al. (2019)

Guo et al. (2019)

Sabbatini et al. (2019)

Sabbatini et al. (2019)

Sabbatini et al. (2019)

Sabbatini et al. (2019)

Sabbatini et al. (2019)

Sabbatini et al. (2019)

Sabbatini et al. (2019)

Sabbatini et al. (2019)

Sabbatini et al. (2019)

Sabbatini et al. (2019)

Sabbatini et al. (2019)

Karkanis et al. (2019)

Karkanis et al. (2019)

Karkanis et al. (2019)

Karkanis et al. (2019)

Bunse et al. (2020)

Wang et al. (2020b)

Wang et al. (2020b)

Wang et al. (2020b) 
intraperitoneal interleukin $1 \beta$ (IL-1 $\beta$ ) in a dose-dependent manner along with improving the survival rate (Seo et al., 2018). Moreover, S. officinalis at a dose of $1 \mathrm{mg} / \mathrm{ml}$ reportedly activated autophagic activity and significantly inhibited $2 \%$ dextran sodium sulfate (DSS)-induced colitis, without damaging the liver, heart, and kidneys in mice (Yasueda et al., 2020).

The chemical components mainly responsible for the antiinflammatory activity exhibited by root parts are phenolic compounds and linear monoterpenes (Su et al., 2018a). In vitro anti-inflammatory tests conducted on zebrafish indicate that the gallic acid group could be the key bioactive group in the terpene glycosides present in S. officinalis, and might function as regulators of the distribution of zebrafish macrophages (Guo et al., 2019). Polysaccharides from S. officinalis, when used at concentrations of $25 \mathrm{mg} / \mathrm{ml}$ and $100 \mathrm{mg} / \mathrm{ml}$, exhibit evident antagonistic effects on P-selectin-mediated leukocyte adhesion, which is a promising target for the treatment of inflammationrelated diseases (Tong et al., 2015). Two acidic polysaccharides purified from S. officinalis (Zhao et al., 2019), and ellagic acid (Seo et al., 2016), which is considered a marker component of $S$. officinalis, have demonstrated significant inhibition of the production of pro-inflammatory cytokines TNF- $\alpha$ and IL- 6 in RAW264.7 cells stimulated by LPS in vitro. In addition, the acidic polysaccharides could effectively improve LPS-induced renal injury in mice by demonstrating acute anti-inflammatory activity (Zhao et al., 2019). Furthermore, ZYM-201, a methyl ester of triterpenoid glycoside, may ameliorate inflammation by inhibiting nuclear factor kappa-B (NF- $\kappa \mathrm{B})$ activation and downregulating the expression of costimulatory molecules on the surface of B cells stimulated by LPS $(1 \mu \mathrm{g} / \mathrm{ml})$.

\section{Antitumor Effects}

Despite huge advances in various antitumor therapies, such as targeted therapy and immunotherapy, chemotherapy continues to be the most commonly used one for the treatment of tumors (Hemminki et al., 2020). Several extracts from genus Sanguisorba have demonstrated significantly greater toxic effects on a variety of tumor cells, compared to the non-tumor cells, in vitro.

It is reported that the water extract of $S$. officinalis, when used at a relatively low dose $\left(\mathrm{IC}_{50}<200 \mu \mathrm{g} / \mathrm{ml}\right)$ and in combination with 5-fluorouracil, could increase the cytotoxic effect on two colorectal cancer cell lines HCT-116 and RKO by promoting the reactive oxygen species-mediated mitochondrial caspasedependent apoptotic pathway (Liu et al., 2016). A similar effect was observed when ellagic acid isolated from the alcohol extracts of S. officinalis was used in combination with cisplatin treatment (Tan et al., 2019), as reported by numerous scientific studies (García-Niño and Zazueta, 2015; Ceci et al., 2018).

Methanol extracts of $S$. officinalis $(40,80$, or $120 \mu \mathrm{g} / \mathrm{ml})$ have demonstrated significant cytotoxic activity against human prostate cancer cells via an intrinsic apoptotic pathway (Choi et al., 2012a), in addition to inhibiting the proliferation of human breast cancer cell lines MCF-7 and MDA-MB-231 by inducing S-phase arrest and triggering the mitochondrial pathway of apoptosis (Wang et al., 2012), and causing the blockage of the G1 phase in B16F10 melanoma cells (Tan et al., 2019).
Triterpenes isolated from $S$. officinalis roots play a major role in the antitumor effect exhibited by this species and demonstrate significant cytotoxicity in various human tumor cell lines, such as BGC-823 cells (human gastric cancer), HeLa cells (human cervical cancer), MCF-7 cells (human breast cancer), SGC7901 cells (human gastric adenocarcinoma), A549 (human lung cancer) and NCI-H460 cells (human large cell lung cancer), and SK-Hep1 (hepatoma cell) and HepG2 cells (human hepatocellular carcinoma), in vitro ( $\mathrm{Hu}$ et al., 2015; Wang et al., 2019a). Interestingly, Mazzio and Soliman (2017) reported that the main role of triterpenes in HeLa cells is to resist mitosis rather than causing cytotoxicity.

Ziyuglycoside I (ZY-I) from S. officinalis roots is reported to induce mitochondria-dependent apoptosis in human retinoblastoma WERI-RB-1 cells, which are representative of the most common intracellular malignancy, by activating P53 in a concentration-dependent manner (Zhu et al., 2017). According to an in vivo experiment, $3,3^{\prime}, 4^{\prime}$-trimethylellagic acid (TMEA, an ellagic acid) derived from $S$. officinalis roots exhibited dose-dependent downregulation of the expression of anti-apoptotic factors $\mathrm{CD} 31$ and $\mathrm{Bcl}-2$ and upregulation of the expressions of apoptotic factors Bax and caspase- 3 in the allograft tumor of SW620 nude mice (Bai et al., 2020b).

Zhu et al. (2013a) were the first to discover that ziyuglycoside II (ZY-II) from S. officinalis roots could inhibit the growth of two classic human breast cancer cell lines MCF-7 and MDA-MB-231 and induce the apoptosis of human colon cancer cells HCT116 and SW480 (Lkhagvasuren and Kim, 2019). The inhibition of proliferation of hepatocellular carcinoma cells caused by ZY- II is reported to be mainly due to increased apoptosis, accumulation of reactive oxygen species, and cell cycle arrest in the G0/G1 phase (Liao et al., 2020), although the apoptosis of gastric carcinoma cells BGC-823 induced by ZY- II applied at a concentration of $25 \mu \mathrm{M}$ would not induce cell cycle arrest (Zhu et al., 2013b). Oral intake of ZY- II (1 or 5 mg/kg) three times per week could reportedly reduce the nuclear factor kappa-B-positive cells and the levels of inflammation-related proteins, promoting azoxymethane-induced colon cancer in $\mathrm{BALB} / \mathrm{c}$ mice (Cheon and Kim, 2019).

In addition to targeting the intrinsic pathway of apoptosis, inhibiting the formation of blood vessels that supply oxygen and essential nutrients to cancer cells is considered another promising approach to cancer treatment.

ZY- II could reportedly inhibit the proliferation, migration and tubule formation of human umbilical vein endothelial cells (HUVECs), probably by blocking the signaling pathway mediated by the vascular endothelial growth factor receptor 2(VEGFR2) and fibroblast growth factor receptor 1 (Nam et al., 2017). TMEA could inhibit the growth of breast cancer cells and angiogenesis of human umbilical vein endothelial cells (Wang et al., 2012). In addition, TMEA could combine with VEGFR2 in the functional area to inhibit the proliferation, migration, tube formation and VEGF expression and downstream signals in HUVECs (Bai et al., 2020a).

The extract of $S$. minor (Cuccioloni et al., 2012) appears to be as effective as that of S. officinalis (Li et al., 2019) in restraining the plasmin-mediated migration of cancer cells and demonstrating excellent antitumor ability against certain cancer cell lines, such as HepG2 (Vanzani et al., 2011; Karkanis et al., 2019). It is 
noteworthy that compared to the leaf and stem extracts of $S$. officinalis, its root extracts exhibit a stronger anticancer activity against most cancer cell lines. Whether this difference is related to the higher content of phenolic compounds in the root system requires further investigation. Although it is reported that under different planting conditions, the roots of half-rate fertilizer $(330 \mathrm{~kg} / \mathrm{ha})$ having the highest content of total phenolic compounds indeed exhibit an increased cytotoxic effect on tumor cell lines (Finimundy et al., 2020). Despite S. minor being a common part of the human diet in the Mediterranean region, its complete potential has not been explored so far as the tissues of this plant might serve as a potential source of natural bioactive compounds that could further be used in medicine.

Currently, while the antitumor activity exhibited by the plants of genus Sanguisorba has been verified in a variety of tumor cell lines in vitro, the in vivo experiments remain insufficient to validate these effects.

\section{Hemostatic Effects}

In China, South Korea, Japan, Siberia, and Europe, S. officinalis is frequently used as a hemostatic agent. In China, S. officinalis plants are often transformed into charcoal of S. officinalis and used clinically to control bleeding. An experimental study on the effect of raw S. officinalis and charred sanguisorba based on the tail-breaking and capillary method demonstrated that while both forms could significantly shorten the duration of bleeding and reduce the clotting time in mice, the effect of charred sanguisorba was significantly stronger than that of raw S. officinalis at an equivalent dose (Zhou, 2014). According to the research of $\mathrm{Ma}$ et al. (2017), thermal analysis techniques could be used to precisely control the temperature and thereby determine the energy changes occurring during the partial carbonizing process of $S$. officinalis.

Consistent with the traditional usage of the plants of genus Sanguisorba, a large number of studies have reported the hemostatic effects exhibited by the plants of this genus in vivo as well as in vitro. Based on the evidence provided by both the Szejk et al. (2017b) and Liu et al. (2018c), the polysaccharide-polyphenolic conjugates in Rosaceae/ Asteraceae plants exhibit various biological activities, such as anticoagulation, radiation protection, anti-platelet and bronchodilatory effects. The polyphenol-polysaccharide conjugate in dried and flowering parts of S. officinalis, the anticoagulant activity of which is reportedly mediated mainly by heparin cofactor II (Pawlaczyk-Graja et al., 2016), are capable of selectively protecting the normal lymphocytes from radiation damage (Zbikowska et al., 2016; Szejk et al., 2017a; Szejk-Arendt et al., 2019).

The hemostatic activity of seven compounds isolated from $S$. officinalis was evaluated using the goat anti-human a2-plasmin inhibitor kit and purified a2-plasmin inhibitor-specific antibody. The results demonstrated that terpene glycosides were responsible for the hemostatic activity, with ZY-I as the main hemostatic component that demonstrated the strongest hemostatic activity $(88.7 \%)$ at a concentration of $0.094 \mathrm{mg} / \mu \mathrm{L}$ (Sun et al., 2012). It was also reported that ZY- I does not exhibit a strong tissue factor -inhibitory activity, and the chemical modification (degumming, esterification, etc.) of its structure, ZY-I deglycoside methyl ester $\left(\mathrm{IC}_{50}=0.46 \mathrm{mM}\right)$ improves its inhibitory activity against TF and TNF-a (Jae et al., 2006).

\section{Antioxidant Activity}

Polysaccharides are the active ingredients of several traditional medicines (Liu et al., 2018a) and the natural antioxidant ingredients of various potential phytopharmaceutical resources (Dkhil et al., 2016), with a long history in ethnopharmacology and little edible toxicity.

S. officinalis is regarded as a herbal medicine with extremely strong antioxidant properties (Liao et al., 2008), which are often evaluated using the DPPH (2,2-dipheny1-1-picrylhydrazy1) removal method and the yeast oxidative stress of the $S$. officinalis polysaccharide. Polysaccharides, when used in a dose range of 552-977 $\mu \mathrm{M}$, exhibit strong radical-scavenging activity and relieve the Saccharomyces cerevisiae-caused oxidative stress induced by oxidants in the body (Zhang et al., 2012a). Ravipati et al. (2012) believed that the antioxidant and anti-inflammatory activities of $S$. officinalis are significantly associated with its phenolic, flavonoid and trace metal contents. In the same year, four phenolic compounds were identified and isolated from the roots of $S$. officinalis, among which fisetinidol- $(4 \alpha-8)$-catechin exhibited the strongest antioxidant activity (Zhang et al., 2012b). S. officinalis was also reported to prevent ischemic brain injury in cultured rat model of cortical neurons and middle cerebral artery occlusion and was proposed as a promising drug for the treatment of neurodegenerative diseases, such as stroke and Alzheimer's disease (Nguyen et al., 2008).

Different methods used for obtaining the extract of $S$. officinalis could result in different contents of total phenols, flavonoids, and terpenoids, and consequently, in different antioxidant activities demonstrated in vitro. When the extracts of $S$. officinalis roots were obtained using cold water (CWE), hot water (HWE) and methanol (ME), the obtained ethyl acetate fractions exhibited dose-dependent free radical scavenging ability (SC) values, as follows: the best $\mathrm{SC}_{50}$ value of $7.58 \mu \mathrm{g} / \mathrm{ml}$ is obtained for HWE, followed by CWE $(12.14 \mu \mathrm{g} / \mathrm{ml}), \mathrm{ME}$ $(16.74 \mu \mathrm{g} / \mathrm{ml})$, CWE-EA $(19.14 \mu \mathrm{g} / \mathrm{ml})$, HWE-EA $(35.81 \mu \mathrm{g} /$ $\mathrm{ml}$ ), and ME-EA $(52.46 \mu \mathrm{g} / \mathrm{ml})$ (Kim et al., 2018a). The chemical compositions of the $S$. officinalis extracts obtained using different methods are also different. The methanol extract presents a flavonoid content that is approximately three times higher than that of the water extract, while the total phenolic content in the water extract is relatively higher (Gawron-Gzella et al., 2016). Moreover, the total phenol content in the methanol extract is two times lower than that in the acetone extract obtained from the same plant (Ginovyan et al., 2020).

The phytochemicals present in S. officinalis are a potent source of exogenous antioxidants that could scavenge the free radicals inside the body, thereby diminishing the effects of photoaging (Yokozawa and Chen, 2001; Mukherjee et al., 2011). Several in vivo and in vitro studies have demonstrated that ZY-I increases the contents of collagen and elastic fibers in a dose-dependent manner and also inhibits the production of the collagen-degrading enzyme MMP-3 in the skin, 
thereby demonstrating an anti-wrinkle effect (Kim et al., 2008; Yun et al., 2019). In a randomized double-blind placebo experiment conducted with 21 Japanese women, it was observed that at the cellular level, it was the S. officinalis root extract, rather than ziyuglycoside-I, that inhibited the hyaluronic acid degradation and consequently exerted the anti-wrinkle effect (Yoshida et al., 2018).

Interestingly, when the chemical constituents of the root, stem, and leaf extracts of $S$. minor were analyzed, it was revealed that the content of polyphenols was significantly higher in the stem and leaf extracts compared to that in the root extracts. Moreover, the highest value of total polyphenol content in $S$. minor was $258 \mathrm{mg} / 100 \mathrm{~g}$, and the content of polyphenols was particularly high (98.2 mmol total phenol/kg) (Romojaro et al., 2013b; Karkanis et al., 2014). Such high contents of biologically active constituent compounds and a strong antioxidant activity are responsible for the role of $S$. minor in the inflammatory process caused by excessive free radical oxidation, such as the inflammatory process associated with Alzheimer's disease (Ceccanti et al., 2019). In addition, the dry powder of S. minor may be utilized for concentrating the vegetable oils with a low natural antioxidant content, such as sunflower oil and corn oil, which would enhance the overall oxidative stability of these oils (Finimundy et al., 2020).

Therefore, due to its rich ingredients and various biological functions, S. minor could be used as a high-in-antioxidant functional food for nutritional supplementation and a natural antioxidant that would replace the artificially synthesized ones, thereby improving the diversity of ingredients in modern cooking. It may also be formulated as a drug to prevent or treat diseases caused due to oxidative stress.

\section{Antibacterial Effects}

Antibiotics represent an important class of therapeutic agents used for the treatment of bacterial infectious diseases (Sun et al., 2004). Unnecessary and excessive use of antibiotics is particularly concerning as this could lead to several adverse drug events, including allergic reactions, end-organ toxic effects, subsequent infection with antibiotic-resistant organisms, and Clostridium difficile infections (Tamma et al., 2017). The demand for novel antibacterial drugs capable of effectively combating drugresistant microorganisms has increased to a great extent (Wright, 2017) and plant materials are generally preferred now for use as natural antibacterial agents in the treatment of various infections (Ginovyan et al., 2020).

Methicillin-resistant Staphylococcus aureus (MRSA) is an important nosocomial pathogen that is resistance to many antibiotics and is, therefore, associated with serious infections. Ethanol extracts of $S$. officinalis $(50 \mathrm{mg} / \mathrm{ml})$ are reported to play important roles in the inhibition of MRSA. At high concentrations $(>7.5 \mathrm{mg} / \mathrm{ml})$, S. officinalis remarkably inhibited the growth of MRSA. However, at low concentrations ( $<2.5 \mathrm{mg} /$ $\mathrm{ml})$, S. officinalis could only cause a slight inhibition of the growth of MRSA (Chen et al., 2015).

The ethanol and methanol extracts of the underground parts and rhizomes of $S$. officinalis exhibit significant antibacterial activity against Gram-positive bacteria, Gram-negative bacteria, and fungi, with all herbal extracts demonstrating a minimum inhibitory concentration value of $0.07-2.50 \mathrm{mg} / \mathrm{ml}$ (Gawron-Gzella et al., 2016). Moreover, S. officinalis might also have the potential to treat local acne owing to the antipropionic acid activity of the different extracts of this species (Kim et al., 2018b). The antimicrobial potential of the crude extracts of $S$. officinalis against various bacterial and yeast strains has been demonstrated using the TLC-Bioautographic Technique (Ginovyan et al., 2020). Furthermore, a purified mulberry polyphenol extract exhibited strong antibacterial activity against Bacillus subtilis.

The research team of Karkanis et al. evaluate the antibacterial property of $S$. minor under different growth conditions which could be related to the content of phenolic compounds and the composition of different phenolic compounds. The extracts from the roots demonstrate a higher antibacterial ability compared with the aerial parts of plants are probably due to the higher content of phenolic compounds in the roots. S. minor extracts were tested for the antibacterial activity of six strains of Bacillus cereus, Enterobacter cloacae, Escherichia coli, Listeria monocytogenes, Staphylococcus aureus and Salmonella typhimurium. The MIC and MBC value extracts ranging from 0.075 to $0.45 \mathrm{mg} / \mathrm{ml}$ and $0.15-0.60 \mathrm{mg} / \mathrm{ml}$, respectively. At the same time, $S$. minor extract also showed antifungal activity.

\section{Antiviral Effects}

Hepatitis B virus (HBV) causes acute and chronic liver disease, both of which place a serious burden on global health due to the associated morbidity and mortality (Indolfi et al., 2019). The limitations of conventional antiviral drugs, such as concerns associated with long-term usage, drug resistance, and virological relapse, have rendered the infectious diseases caused by $\mathrm{HBB}$ almost incurable so far. KCT-01, a novel herbal formula developed for working against the $\mathrm{HBV}$, is composed of mugwort, S. officinalis and turmeric. KCT-01, when applied at $250 \mu \mathrm{g} / \mathrm{ml}$, was sufficient to reduce the secretion of both HBsAg and HBeAg in HepG2 cells to below $50 \%$ compared to the mock-treated control. The antiviral effect of KCT-01 was confirmed in a mouse hydrodynamic injection model, which demonstrated inhibition of HBV replication and the production of inflammatory cytokines, while no toxicity was observed, indicating that KCT-01 alone or in combination with entecavir has the potential to serve as an antiviral agent (Kim et al., 2018a).

Previously, a study had demonstrated that the levels of extracellular HBV virion DNA were decreased, and the secretion of HBsAg was inhibited in a dose-dependent manner with the use of $S$. officinalis extract (SOE) at concentrations ranging from 64 to $128 \mu \mathrm{g} / \mathrm{ml}$ (Kim et al., 2001). In addition, the extract exhibited significant inhibitory effects on both CCR5 and CXCR4 tropic human immunodeficiency virus-1 (ADA and $\mathrm{HXB} 2$ ), with $\mathrm{IC}_{50}$ values of $1.91 \pm 0.16 \mu \mathrm{g} / \mathrm{ml}$ and $3.70 \pm 0.53 \mu \mathrm{g} / \mathrm{ml}$, respectively. SOE also inhibited simian immunodeficiency virus infection, although it failed to block the vesicular stomatitis virus (VSV), SARS-CoV, and influenza H5N1 pseudoviruses (Liang et al., 2013). The methanol extract of Sanguisorba 
officinalis; however, exerts a certain inhibitory effect on the replication of coronavirus (Gawron-Gzella et al., 2016). Activity high-throughput screening assay was employed to screen 190 herbal extracts for the evaluation of their biological activities, and it was revealed that 14 of these extracts, including the extract of $S$. officinalis, significantly inhibited the activity of neuraminidase (the main drug target for antiinfluenza virus therapy), with $\mathrm{IC}_{50}$ values of these extracts ranging from 4.1 to $9.6 \mu \mathrm{g} / \mathrm{ml}$ (Liu et al., 2018b). ZY-II reportedly inhibits the cell growth and rotavirus replication in a dose-dependent and time-dependent manner, in addition to inhibiting the TLR4/NF- $\kappa \mathrm{B}$ pathway and the inflammatory response, while improving rotavirus-induced diarrhea (Liao et al., 2020).

The majority of the plants belonging to genus Sanguisorba exhibit a certain level of antiviral activity, particularly the extract of $S$. minor, which was demonstrated to significantly inhibit herpes simplex virus type 1 (DNA virus) and VSV (RNA virus) at non-toxic concentrations of 50-125 mg/ml (Choi et al., 2012b).

Further detailed and comprehensive research should be planned and executed to explore and develop improved drugs capable of controlling the human immunodeficiency virus, HBV, and other viruses.

\section{Neuroprotective Effects}

Natural compounds derived from medicinal and edible plants have attracted the attention of scholars exploring novel treatment methods for neurological diseases. Catechin (and not gallic acid) present in the root of S. officinalis in the concentration range of $10-50 \mu \mathrm{g} / \mathrm{ml}$ reportedly inhibits the neuronal death induced by $\mathrm{H}_{2} \mathrm{O}_{2}(100 \mu \mathrm{M})$ by eliminating the free radical activity in neurons. In a study conducted using the in vivo model of ischemic brain injury in rats with middle cerebral artery occlusion, the oral administration of 10 or $30 \mathrm{mg} / \mathrm{kg}$ S. officinalis was observed to confer a significant protective effect in terms of the volume of cerebral infarction and cerebral edema in rats, which was the first proof of Neuroprotective effect in antioxidant-caused brain damage (Nguyen et al., 2008). In the same year, another study reported that the methanol extract of $S$. officinalis could prevent $A \beta(25-35)$-induced neuronal cell damage in vitro and that the gallic acid isolated from this extract conferred a certain level of protection against the neurotoxic effect to the $A \beta(25-35)$-induced cortical neurons in rats (Ban et al., 2008).

The amyloid hypothesis has dominated the research on Alzheimer's disease (AD) for nearly 30 years now (Ennerfelt and Lukens, 2020). This implies that S. officinalis could provide a novel potential therapeutic approach for controlling the progress of neurodegeneration in an $\mathrm{AD}$-affected brain, while also being a promising drug for the treatment of other neurodegenerative diseases, such as stroke.

Sanguiin H-11 (SH-11) derived from the root of S. officinalis also exhibits a strong antioxidant activity. SH-11 acts as a powerful antioxidant that significantly reduces the glutamateinduced accumulation of reactive oxygen species and a calcium ion influx in mouse clonal hippocampal HT22 cells. Apoptotic cells exhibit effective neuroprotective activity via glutamateinduced phosphorylation of mitogen-activated protein kinases, including the extracellular signal-related kinases $1 / 2$, c-Jun
N-terminal kinase, and p38, and this activity was decreased significantly by SH-11 (Song et al., 2019).

\section{Hematopoietic Effects}

Clinical practice in China in the past few decades has confirmed that the extract of $S$. officinalis increases the number of white blood cells and reduces the bone marrow toxicity caused by antitumor treatments.

Myelosuppressive mice induced by exposure to cyclophosphamide and ${ }^{60} \mathrm{Co}-\gamma$ radiation for 13 days were tested for the efficacy of total saponins of $S$. officinalis at the doses of $1.6 \mathrm{mg} / \mathrm{kg}, 0.8 \mathrm{mg} / \mathrm{kg}$ and $0.4 \mathrm{mg} / \mathrm{kg}$ administered orally. The results demonstrated that survival was promoted through the activation of focal adhesion kinase (FAK) and extracellular signal-regulated kinase $1 / 2(\operatorname{Erk} 1 / 2)$ and the modulation of cytokine production in the bone marrow (Chen et al., 2017) Two ellagic acid compounds isolated from the ethyl acetate extracts of $S$. officinalis root promoted megakaryocyte progenitor cells in a dose-dependent $(10 \mu \mathrm{g} / \mathrm{ml}$ or $20 \mu \mathrm{g} / \mathrm{ml})$ and time-dependent (4, 8 and 12 days) manner, leading to their proliferation and induction of megakaryocyte differentiation (Gao et al., 2014).

\section{Hypoglycemic and Lipid-Lowering Effects}

Obesity, hyperglycemia, and hypertension or dyslipidemia are the three medical conditions that usually occur simultaneously in patients and are often described as metabolic syndrome that increases the risk of diabetes and cardiovascular disease in the affected patients (Samson and Garber, 2014). In China, Sanguisorba $\times$ tenuifolia Fisch. ex Link (S. tenuifolia) is used commonly for treating diabetes. The ethyl acetate layer in the alcohol extract of the roots of $S$. tenuifolia was observed to be rich in triterpenes, which could inhibit plasma glucose levels in diabetic rats induced by alloxan. These triterpenoids have been reported for the first time in this plant variety, and they demonstrate inhibitory activity against a-glucosidase (Kuang et al., 2011). These plants are used as an alternative medicine to replace $S$. officinalis in diabetes.

In comparison to ZY-I, chemically modified ziyuglycoside II methyl ester (ZG02-ME) exhibits a better performance in the treatment of type 2 diabetes. A single dose of ZY- I or ZG02-ME ( $5 \mathrm{mg} / \mathrm{kg}$ body weight) each day for 1 week is capable of lowering the blood sugar levels by $2.6 \%$ or $11.4 \%$, respectively, in addition to significantly decreasing the levels of glycated hemoglobin (HbAlc) and serum insulin. Further evaluation of the antidiabetic effect of ZG02-ME consumed for 4 consecutive weeks revealed that it could significantly reduce blood glucose levels in a dose-dependent manner, by $11.1,17.6$ and $22.4 \%$ at the dose of 1 , 3 and $5 \mathrm{mg} / \mathrm{kg}$, respectively (Son et al., 2015). Oral administration of ZYM-201 sodium succinate $(1-10 \mathrm{mg} / \mathrm{kg})$, produced as a chemical modification of the triterpene glycosides isolated from $S$. officinalis, reduces the diet-induced body weight and liver weight, and returns the serum triglyceride and total cholesterol levels to their normal ranges in hyperlipidemic rats (Choi et al., 2011) as well as in Hyperlipidemic rats with hyperglycemia (Choi et al., 2012a). In addition, this compound normalizes the changes that had occurred in the lipid metabolism 
TABLE 2 | Summary of the contemporary clinical uses of S. officinalis.

No.

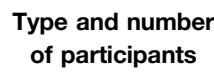

11822 patients with bleeding haemorrhoids (age range,17-87 years old)

221 healthy Japanese women (age range, 34-56 years old)

320 females in good general health (age range, 35-53 years old)

4120 confirmed diagnosis of steroid-dependent ulcerative colitis

(age range, 18-65 years old)

560 patients with mild-to-moderately initial onset or relapsed active ulcerative colitis (UC)

(age range, 28-52 years old)

Herbal constituents

Herbal drug effects

References

Radix Sanguisorbae formulations

S. officinalis root extract and ziyuglycoside I

ziyuglycoside I

Radix Sanguisorbae formulations

Enema of Guanchang Recipe (6 herbs including treat active UC Radix Sanguisorbae) stop bleeding from

haemorrhoids

anti-wrinkle activity on human

facial skin

anti-wrinkle activity

steroid-dependent ulcerative colitis
Gan et al. (2010)

Yoshida et al. (2018)

Kim et al. (2008)

Zheng et al.

(2017)

He et al. (2012) due to hyperglycemia and high-fat diets, allowing its use for improving alcohol-induced hyperlipidemia (Cho et al., 2014).

\section{CLINICAL INVESTIGATIONS ON S. OFFICINALIS}

The clinical incidence of malignant tumors has been increasing in recent years. Radiotherapy is one of the main methods used for treating malignant tumors. However, radiotherapy often causes bone marrow suppression, which greatly reduces the peripheral white blood cell count greatly and affects the outcomes of radiotherapy to a certain extent. Drugs such as Squalanol are used commonly in the treatment of leukopenia after radiotherapy, although these drugs are more likely to cause adverse reactions in patients after treatment, which reduces the treatment tolerance.

Sanguisorba officinalis white tablet has been clinically used for the treatment of leukopenia caused by continuous application of radiotherapy and chemotherapy in cancer for over 10 years (Zhu et al., 2020b). This method of tablet treatment effectively compensated for the deficiency of shark liver alcohol and was widely accepted by patients. Ziyuglycoside $\mathrm{I}$, which is one of the main active ingredients

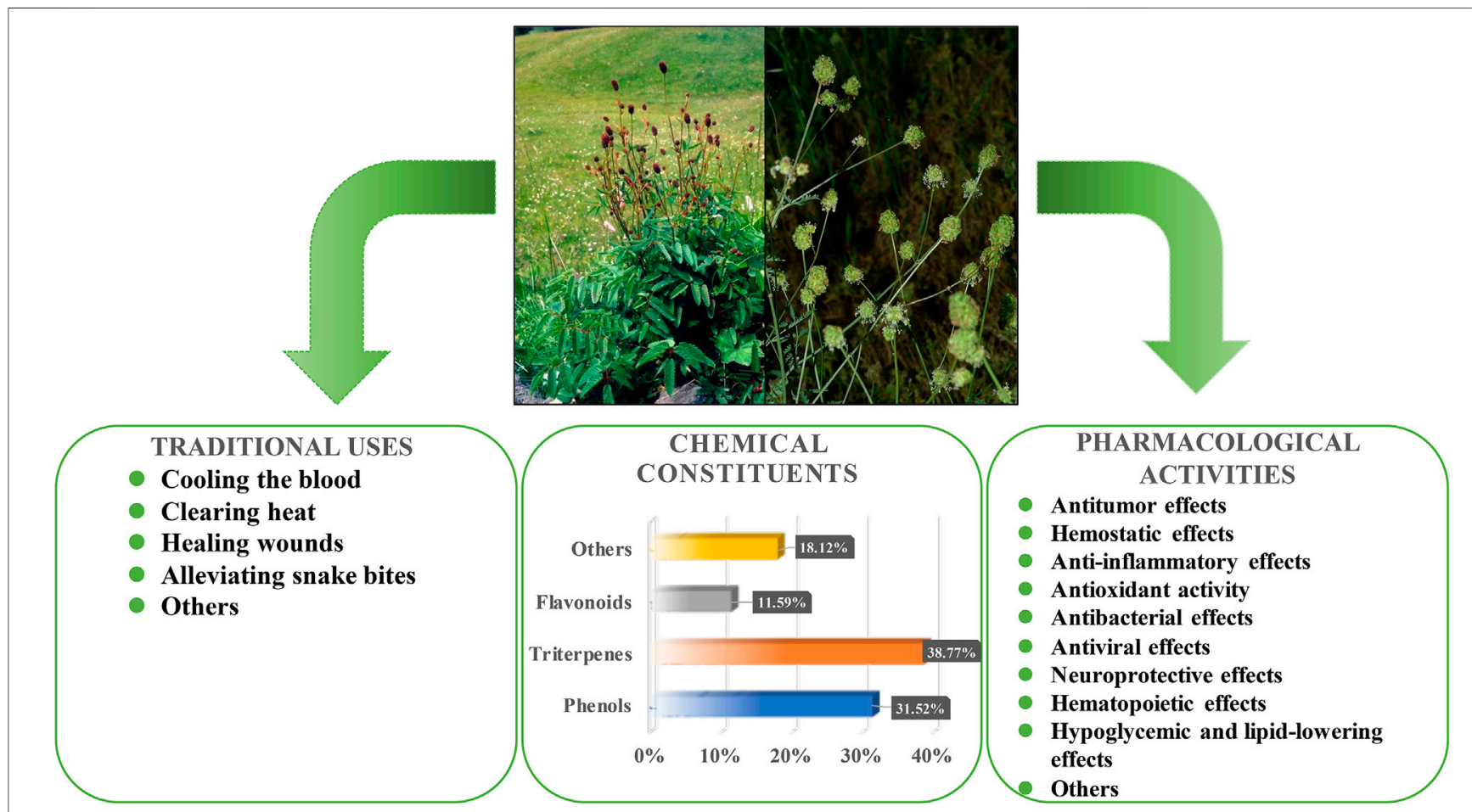

FIGURE 5 | Traditional applications, chemical compositions and pharmacological activities of S. officinalis and S. minor. 
in the Sanguisorba officinalis white tablet, is clinically proven to reduce leukopenia. Since ZY-I exhibits low solubility and permeability when administered orally, a ZY-I-loaded selfmicroemulsifying drug delivery system has been developed to improve the bioavailability and intestinal absorption of ZY-I, thereby increasing the pharmacokinetics and pharmacodynamic activity of leukocyte (Xiong et al., 2019). In addition, through searching Cochrane Library database (Cochrane Library, 2021), records in the four trials, there prescription containing composition $S$. officinalis treatment of ulcerative colitis (Table 2).

Data from large-scale, randomized, double-blind, multi-center trials are needed to confirm the efficacy and safety of the clinical use of traditional Chinese medicine. These clinical trials should use standardized efficacy indicators, and should include an assessment of adverse events.

\section{TOXICITY}

So far, there have been limited reports on the toxicity caused by the different species of Sanguisorba in humans, and the major safety concern related to these species have been confined to the veterinary field. To date, no harmful components, such as alkaloids, have been reported in S. minor and S. officinalis (Sabbatini et al., 2019). Egorova et al. (2018) investigated the medicinal products of $S$. officinalis (rhizome and root) for the presence of heavy metals and other ecotoxic substances and reported no toxicity, thereby providing evidence for the safety and non-toxicity of $S$. officinalis. Nonetheless, to establish the safety of plants belonging to genus Sanguisorba, further research involving a comprehensive safety assessment is necessary.

\section{PERSPECTIVES AND DISCUSSION}

This review uses $S$. officinalis and $S$. minor as representatives of the genus Sanguisorba, providing a comprehensive understanding of the traditional application, chemical composition and pharmacological activities of genus Sanguisorba (Figure 5). It is well recognized that the various ingredients present in herbs, besides producing a synergistic beneficial effect, also reduce the toxicity caused by a single compound. However, the biggest problem encountered when using traditional herbal treatments is the inability to ensure

\section{REFERENCES}

Bai, C., Sun, Y., Pan, X., Yang, J., Li, X., Wu, A., et al. (2020a). Antitumor Effects of Trimethylellagic Acid Isolated from Sanguisorba Officinalis L. On Colorectal Cancer via Angiogenesis Inhibition and Apoptosis Induction. Front. Pharmacol. 10, 1646. doi:10.3389/fphar.2019.01646

Bai, C., Zhang, Z., Zhou, L., Zhang, H. Y., Chen, Y., and Tang, Y. (2020b). Repurposing Ziyuglycoside II against Colorectal Cancer via Orchestrating Apoptosis and Autophagy. Front. Pharmacol. 11 (9), 576547. doi:10.3389/fphar.2020.576547 the quality and consistency of the herbal extracts. In recent years, genus Sanguisorba has been attracting increasing attention, with several of its traditional uses explored and investigated for potential use in current medicine. However, the reports on the alkaloids or other harmful ingredients, toxicity to target organs, and the safety of Sanguisorba are scarce. Therefore, further studies on the toxicity and pharmacokinetics of the genus Sanguisorba plants are warranted.

With advancements in the separation and purification of the active ingredients in the plants of genus Sanguisorba, the detailed research of its species pharmacology and molecular mechanism has also improved greatly, which could, in turn, ensure further precise pharmacological effects. Additionally, the separation of the chemical components of genus Sanguisorba may become a good candidate for chemotaxonomic markers. The application of novel technologies, such as high-throughput screening, would also greatly improve the probability and quality of novel drug discovery and subsequent clinical implications in the future.

\section{AUTHOR CONTRIBUTIONS}

All authors contributed to the study conception and design. Conceptualization, Material preparation, data collection and analysis were performed by PZ, JL, QC, LW, JY, AW, NJ, JC, WZ, JZ, and JW. The first draft of the manuscript was written by $\mathrm{PZ}$, JL, QC, and all authors commented on previous versions of the manuscript.

\section{FUNDING}

This research was funded by grants from the National Natural Science Foundation of China (Grant Nos 81774013, 81804221 and 82074129), the National Major Science and Technology Project of the Ministry of Science and Technology of China (Grant No. 2018ZX09721004-006-004), the Science and Technology Planning Project of Sichuan Province, China (Grant Nos 2018JY0237, 2019JDPT0010, 2019YJ0473 and 19PTDJ0026), Educational Commission of Sichuan Province, China (Grant Nos 18TD0051 and 18ZA0525), Science and Technology Program of Luzhou, China (Grant No. 2017-S-39 (3/5), 2020LZXNYDZ03 and 2018LZXNYD-ZK49), the Schoollevel Fund of Southwest Medical University (Grant Nos 2017ZRZD-017 and 2017-ZRQN-081).

Ban, J. Y., Nguyen, H. T., Lee, H. J., Cho, S. O., Ju, H. S., Kim, J. Y., et al. (2008) Neuroprotective Properties of Gallic Acid from Sanguisorbae Radix on Amyloid Beta Protein (25--35)-induced Toxicity in Cultured Rat Cortical Neurons. Biol. Pharm. Bull. 31 (1), 149-153. doi:10.1248/bpb.31.149

Biernasiuk, A., Wozniak, M., and Bogucka-Kocka, A. (2015). Determination of Free and Bounded Phenolic Acids in the Rhizomes and Herb of Sanguisorba Officinalis L. Curr. Issues Pharm. Med. Sci. 28 (4), 254-256. doi:10.1515/cipms2015-0083

Bunse, M., Lorenz, P., Stintzing, F. C., and Kammerer, D. R. (2020). Characterization of Secondary Metabolites in Flowers of Sanguisorba 
Officinalis L. By HPLC-DAD-MSn and GC/MS. Chem. Biodivers. 17 (4), e1900724. doi:10.1002/cbdv.201900724

Bączek, K. (2015). Accumulation of Biomass and Phenolic Compounds in Polish and Mongolian Great burnet (Sanguisorba Officinalis L.) Populations. Herba Pol. 60 (3), 44-55. doi:10.2478/hepo-2014-0015

Caporaso, N., Armento, V., and Sacchi, R. (2015). Volatile Profile of Conciato Romano Cheese, a Traditional Italian Cheese, during Ripening. Eur. J. Lipid Sci. Technol. 117 (9), 1422-1431. doi:10.1002/ejlt.201400153

Ceccanti, C., Landi, M., Rocchetti, G., Miras Moreno, M. B., Lucini, L., Incrocci, L., et al. (2019). Hydroponically Grown Sanguisorba Minor Scop.: Effects of Cut and Storage on Fresh-Cut Produce. Antioxidants (Basel) 8, 631. doi:10.3390/ antiox8120631

Ceci, C., Lacal, P. M., Tentori, L., De Martino, M. G., Miano, R., and Graziani, G. (2018). Experimental Evidence of the Antitumor, Antimetastatic and Antiangiogenic Activity of Ellagic Acid. Nutrients 10 (11), 1-23. doi:10.3390/nu10111756

Chen, X., Li, B., Gao, Y., Ji, J., Wu, Z., and Chen, S. (2017). Saponins from Sanguisorba Officinalis Improve Hematopoiesis by Promoting Survival through FAK and Erk1/2 Activation and Modulating Cytokine Production in Bone Marrow. Front. Pharmacol. 8 (3), 130. doi:10.3389/fphar.2017.00130

Chen, X., Shang, F., Meng, Y., Li, L., Cui, Y., Zhang, M., et al. (2015). Ethanol Extract of Sanguisorba Officinalis L. Inhibits Biofilm Formation of MethicillinResistant Staphylococcus aureus in an Ica-dependent Manner. J. Dairy Sci. 98 (12), 8486-8491. doi:10.3168/jds.2015-9899

Cheon, H.-J., and Kim, J.-K. (2019). Ziyuglycoside II Attenuates Tumorigenesis in Experimental Colitis-Associated colon Cancer. J. Life Sci. 29, 941-948. doi:10.5352/JLS.2019.29.9.941

Chin, Y. W., Balunas, M. J., Chai, H. B., and Kinghorn, A. D. (2006). Drug Discovery from Natural Sources. AAPS J. 8, E239-E253. doi:10.1007/ bf02854894

Cho, J. Y., Choi, J., Park, J. G., Yi, Y. S., Hossen, M. J., Kim, H., et al. (2014). Alcohol-induced Hyperlipidemia Is Ameliorated by Orally Administered DWP208, a Sodium Succinate Form of ZYM201. Korean J. Physiol. Pharmacol. 18 (6), 469-474. doi:10.4196/kjpp.2014.18.6.469

Cho, J., Yoo, E., Cha, B., Park, H.-J., Rhee, M., and Han, Y. (2006). The Inhibitory Effect of Triterpenoid Glycosides Originating fromSanguisorba Officinalison Tissue Factor Activity and the Production of TNF- $\alpha$. Planta Med. 72, 1279-1284. doi:10.1055/s-2006-947257

Choi, E. S., Kim, J. S., Kwon, K. H., Kim, H. S., Cho, N. P., and Cho, S. D. (2012). Methanol Extract of Sanguisorba Officinalis L. With Cytotoxic Activity against PC3 Human Prostate Cancer Cells. Mol. Med. Rep. 6, 670-674. doi:10.3892/ mmr.2012.949

Choi, J., Kim, M. Y., Cha, B. C., Yoo, E. S., Yoon, K., Lee, J., et al. (2012). ZYM-201 Sodium Succinate Ameliorates Streptozotocin-Induced Hyperlipidemic Conditions. Planta Med. 78 (1), 12-17. doi:10.1055/s-0031-1280219

Choi, J., Yu, T., Cha, B. C., Rhee, M. H., Yoo, E. S., Kim, M. Y., et al. (2011). Modulatory Effects of ZYM-201 Sodium Succinate on Dietary-Induced Hyperlipidemic Conditions. Pharmazie 66 (10), 791-797.

Cochrane Library (2021). Sanguisorba. Available at: https://www.cochranelibrary. com (Accessed August 30, 2021).

Cuccioloni, M., Bonfili, L., Mozzicafreddo, M., Cecarini, V., Eleuteri, A. M., and Angeletti, M. (2012). Sanguisorba Minor Extract Suppresses Plasmin-Mediated Mechanisms of Cancer Cell Migration. Biochim. Biophys. Acta 1820 (7), 1027-1034. doi:10.1016/j.bbagen.2012.02.002

Dkhil, M. A., Delic, D., El Enshasy, H. A., and Abdel Moneim, A. E. (2016). Medicinal Plants in Therapy: Antioxidant Activities. Oxidative Med. Cell Longevity 2016, 1. doi:10.1155/2016/7468524

Egorova, N., Egorova, I., Maltseva, E., and Sukhikh, A. (2018). Ecotoxicants Content of Sanguisorba Officinalis L., Growing on Mining Disturbed Lands of Kemerovo Region. E3s Web Conf. 41, 02023. doi:10.1051/e3sconf/ 20184102023

Ekor, M. (2014). The Growing Use of Herbal Medicines: Issues Relating to Adverse Reactions and Challenges in Monitoring Safety. Front. Pharmacol. 4 (4), 177. doi:10.3389/fphar.2013.00177

Ennerfelt, H. E., and Lukens, J. R. (2020). The Role of Innate Immunity in Alzheimer's Disease. Immunol. Rev. 297, 225-246. doi:10.1111/imr.12896

Eyong, K. O., Bairy, G., Eno, A. A., Taube, J., Hull, K. G., Folefoc, G. N., et al. (2017). Triterpenoids from the Stem Bark of Vitellaria Paradoxa (Sapotaceae) and
Derived Esters Exhibit Cytotoxicity against a Breast Cancer Cell Line. Med. Chem. Res. 27 (1), 268-277. doi:10.1007/s00044-017-2059-7

Fang, R., Wu, R., Zuo, Q., Yin, R., Zhang, C., Wang, C., et al. (2018). Sophora Flavescens Containing-QYJD Formula Activates Nrf2 Anti-oxidant Response, Blocks Cellular Transformation and Protects against DSSInduced Colitis in Mouse Model. Am. J. Chin. Med. 46 (7), 1-15. doi:10.1142/S0192415X18500829

Finimundy, T. C., Karkanis, A., Fernandes, Â., Petropoulos, S. A., Calhelha, R., Petrović, J., et al. (2020). Bioactive Properties of Sanguisorba Minor L. Cultivated in central Greece under Different Fertilization Regimes. Food Chem. 327 (3), 127043-127048. doi:10.1016/j.foodchem.2020.127043

Fry, E. L., Johnson, G. N., Hall, A. L., Pritchard, W. J., Bullock, J. M., and Bardgett, R. D. (2018). Drought Neutralises Plant-Soil Feedback of Two Mesic Grassland Forbs. Oecologia 186, 1113-1125. doi:10.1007/s00442-018-4082-x

Gan, T., Liu, Y. D., Wang, Y., and Yang, J. (2010). Traditional Chinese Medicine Herbs for Stopping Bleeding from Haemorrhoids. Cochrane Database Syst. Rev. 6 (10), CD006791. doi:10.1002/14651858.CD006791.pub2

Gao, X., Wu, J., Zou, W., and Dai, Y. (2014). Two Ellagic Acids Isolated from Roots of Sanguisorba Officinalis L. Promote Hematopoietic Progenitor Cell Proliferation and Megakaryocyte Differentiation. Molecules 19 (4), 5448-5458. doi:10.3390/molecules 19045448

García-Niño, W. R., and Zazueta, C. (2015). Ellagic Acid: Pharmacological Activities and Molecular Mechanisms Involved in Liver protection. Pharmacol. Res. 97, 84-103. doi:10.1016/j.phrs.2015.04.008

Gawron-Gzella, A., Witkowska-Banaszczak, E., Bylka, W., Dudek-Makuch, M., Odwrot, A., and Skrodzka, N. (2016). Chemical Composition, Antioxidant and Antimicrobial Activities of Sanguisorba Officinalis L. Extracts. Pharm. Chem. J. 50 (4), 244-249. doi:10.1007/s11094-016-1431-0

Ginovyan, M., Ayvazyan, A., Nikoyan, A., Tumanyan, L., and Trchounian, A. (2020). Phytochemical Screening and Detection of Antibacterial Components from Crude Extracts of Some Armenian Herbs Using TLC-Bioautographic Technique. Curr. Microbiol. 77, 1223-1232. doi:10.1007/s00284-020-01929-0

Guarrera, P. M., and Savo, V. (2016). Wild Food Plants Used in Traditional Vegetable Mixtures in Italy. J. Ethnopharmacol. 185, 202-234. doi:10.1016/ j.jep.2016.02.050

Guo, D. L., Chen, J. F., Tan, L., Jin, M. Y., Ju, F., Cao, Z. X., et al. (2019). Terpene Glycosides from Sanguisorba Officinalis and Their Anti-inflammatory Effects. Molecules 24 (16), 2906. doi:10.3390/molecules 24162906

Hachiya, A., Kobayashi, A., Ohuchi, A., Kitahara, T., and Takema, Y. (2001). The Inhibitory Effect of an Extract of Sanguisorba Officinalis L. On Ultraviolet B-Induced Pigmentation via the Suppression of EndothelinConverting Enzyme-1alpha. Biol. Pharm. Bull. 24 (6), 688-692. doi:10.1248/ bpb. 24.688

He, H. H., Shen, H., and Zheng, K. (2012). [Observation of the Curative Effect of Qingchang Huashi Recipe for Treating Active Ulcerative Colitis of InnerAccumulation of Damp-Heat Syndrome]. Zhongguo Zhong Xi Yi Jie He Za Zhi 32 (12), 1598-1601.

Hemminki, O., Dos Santos, J. M., and Hemminki, A. (2020). Oncolytic Viruses for Cancer Immunotherapy. J. Hematol. Oncol. 13 (1), 84. doi:10.1186/s13045-02000922-1

Holloway, P. S., and Matheke, G. E. (2003). Seed Germination of Burnet, Sanguisorba Spp. Native Plants J. 4 (2), 95-99. doi:10.3368/ npj.4.2.95NPJFall2003

Hu, J., Shi, X. D., Chen, J. G., and Li, C. S. (2012). Two New Rhamnopyranosides of Neolignans from Sanguisorba Officinalis. J. Asian Nat. Prod. Res. 14 (2), 171-175. doi:10.1080/10286020.2011.634803

Hu, J., Song, Y., Li, H., Yang, B., Mao, X., Zhao, Y., et al. (2015). Cytotoxic Triterpene Glycosides from the Roots of Sanguisorba Officinalis. Arch. Pharm. Res. 38 (6), 984-990. doi:10.1007/s12272-014-0477-3

Im, S. H., Wang, Z., Lim, S. S., Lee, O. H., and Kang, I. J. (2017). Bioactivity-guided Isolation and Identification of Anti-adipogenic Compounds from Sanguisorba Officinalis. Pharm. Biol. 55 (1), 2057-2064. doi:10.1080/ 13880209.2017.1357736

Indolfi, G., Easterbrook, P., Dusheiko, G., Siberry, G., Chang, M. H., Thorne, C., et al. (2019). Hepatitis B Virus Infection in Children and Adolescents. Lancet Gastroenterol. Hepatol. 4 (6), 466-476. doi:10.1016/S2468-1253(19)30042-1

International Plant Name Index (2021). Sanguisorba. Available at: https://www. ipni.org/?q=Sanguisorba (Accessed August 30, 2021). 
Jang, E., Inn, K. S., Jang, Y. P., Lee, K. T., and Lee, J. H. (2018a). Phytotherapeutic Activities of Sanguisorba Officinalis and its Chemical Constituents: A Review. Am. J. Chin. Med. 46 (2), 299-318. doi:10.1142/S0192415X18500155

Jang, E., Kim, S., Lee, N.-R., Kim, H., Chae, S., Han, C.-W., et al. (2018b). Sanguisorba Officinalis Extract, Ziyuglycoside I, and II Exhibit Antiviral Effects against Hepatitis B Virus. Eur. J. Integr. Med. 20 (3), 165-172. doi:10.1016/j.eujim.2018.05.009

Ji, H., Ahn, K., Cho, H., Kim, H. E., Kim, Y., and Kim, O. (2018). Sanguisorba Officinalis L. Extracts Activate Wnt/ $/$-Catenin Pathway, and Subsequently Control Adipo-Osteogenic Differentiation. Biochem. Biophys. Res. Commun. 504 (1), 352-358. doi:10.1016/j.bbrc.2018.08.196

Jo, S., Ryu, J., Kim, H., Kim, M., Ryu, M. H., Kim, H., et al. (2015). Antiinflammatory Effects of Sanguisorbae Radix on Contact Dermatitis Induced by Dinitrofluorobenzene in Mice. Chin. J. Integr. Med. 26, 688-693. doi:10.1007/s11655-015-2148-8

Jung, D. W., Lee, O. H., and Kang, I. J. (2016). Sanguisorba Officinalis L. Extracts Exert Antiobesity Effects in 3T3-L1 Adipocytes and C57BL/6J Mice Fed HighFat Diets. J. Med. Food 19 (8), 768-779. doi:10.1089/jmf.2016.3704

Karkanis, A. C., Fernandes, Â., Vaz, J., Petropoulos, S., Georgiou, E., Ciric, A., et al. (2019). Chemical Composition and Bioactive Properties of Sanguisorba Minor Scop. Under Mediterranean Growing Conditions. Food Funct. 10 (3), 1340-1351. doi:10.1039/c8fo02601g

Karkanis, A., Vellios, E., Thomaidis, T., Bilalis, D., Efthimiadou, A., and Travlos, I. (2014). Phytochemistry and Biological Properties of Burnet Weed (Sanguisorba spp.): A Review. Not Sci. Biol. 6 (4), 395-398. doi:10.15835/nsb649471

Kew Botanical Garden (2021b). Sanguisorba Minor Scop. Available at: http://powo. science.kew: taxon/741402-1 (Accessed August 30, 2021).

Kew Botanical Garden (2021a). Sanguisorba Officinalis L. Available at: http://powo. science.kew: taxon/741402-1 (Accessed August 30, 2021).

Kim, H., and Song, M. J. (2011). Analysis and Recordings of Orally Transmitted Knowledge about Medicinal Plants in the Southern Mountainous Region of Korea. J. Ethnopharmacol. 134 (3), 676-696. doi:10.1016/j.jep.2011.01.024

Kim, H., Jang, E., Kim, S.-Y., Choi, J.-Y., Lee, N.-R., Kim, D.-S., et al. (2018). Preclinical Evaluation ofIn VitroandIn VivoAntiviral Activities of KCT-01, a New Herbal Formula against Hepatitis B Virus. Evidence-Based Complement. Altern. Med. 2018, 1-9. doi:10.1155/2018/10735092018

Kim, S., Oh, S., Noh, H. B., Ji, S., Lee, S. H., Koo, J. M., et al. (2018). In Vitro antioxidant and Anti-propionibacterium Acnes Activities of Cold Water, Hot Water, and Methanol Extracts, and Their Respective Ethyl Acetate Fractions, from Sanguisorba Officinalis L. Roots. Molecules 23 (11). doi:10.3390/ molecules 23113001

Kim, T. G., Kang, S. Y., Jung, K. K., Kang, J. H., Lee, E., Han, H. M., et al. (2001). Antiviral Activities of Extracts Isolated from Terminalis Chebula Retz., Sanguisorba Officinalis L., Rubus Coreanus Miq. And Rheum Palmatum L. against Hepatitis B Virus. Phytother Res. 15, 718-720. doi:10.1002/ptr.832

Kim, Y. H., Chung, C. B., Kim, J. G., Ko, K. I., Park, S. H., Kim, J. H., et al. (2008). Anti-wrinkle Activity of Ziyuglycoside I Isolated from a Sanguisorba Officinalis Root Extract and its Application as a Cosmeceutical Ingredient. Biosci. Biotechnol. Biochem. 72 (2), 303-311. doi:10.1271/bbb.70268

Kuang, H. X., Li, H. W., Wang, Q. H., Yang, B. Y., Wang, Z. B., and Xia, Y. G. (2011). Triterpenoids from the Roots of Sanguisorba Tenuifolia Var. Alba. Molecules 16 (6), 4642-4651. doi:10.3390/molecules 16064642

Lee, N. H., Lee, M. Y., Lee, J. A., Jung, D. Y., Seo, C. S., Kim, J. H., et al. (2010). Antiasthmatic Effect of Sanguisorba Officinalis L. And Potential Role of Heme Oxygenase-1 in an Ovalbumin-Induced Murine Asthma Model. Int. J. Mol. Med. 26 (4), 201-208. doi:10.3892/ijmm.10.3892/ijmm_00000453

Lenzi, A., Orlandini, A., Bulgari, R., Ferrante, A., and Bruschi, P. (2019). Antioxidant and mineral Composition of Three Wild Leafy Species: A Comparison between Microgreens and Baby Greens. Foods 8 (10), 487. doi:10.3390/foods 8100487

Li, L., Kong, J., Yao, C. H., Liu, X. F., and Liu, J. H. (2019). Rapid Identification of Urokinase Plasminogen Activator Inhibitors from Traditional Chinese Medicines Based on Ultrafiltration, LC-MS and In Silico Docking. J. Pharm. Biomed. Anal. 164, 241-248. doi:10.1016/j.jpba.2018.10.036

Liang, J., Chen, J., Tan, Z., Peng, J., Zheng, X., Nishiura, K., et al. (2013). Extracts of Medicinal Herb Sanguisorba Officinalis Inhibit the Entry of Human Immunodeficiency Virus Type One. Yao Wu Shi Pin Fen Xi 21 (4), S52-S58. doi:10.1016/j.jfda.2013.09.034
Liao, H., Banbury, L. K., and Leach, D. N. (2008). Antioxidant Activity of 45 Chinese Herbs and the Relationship with Their TCM Characteristics. Evid. Based. Complement. Alternat. Med. 5 (4), 429-434. doi:10.1093/ecam/nem054

Liao, W., Fan, L., Zheng, Z., Liu, H., Deng, H., Li, M., et al. (2020). Ziyuglycoside II Exerts Antiproliferative and Antimetastasis Effects on Hepatocellular Carcinoma Cells. Anticancer Drugs 31 (8), 819-827. doi:10.1097/ cad.0000000000000918

Liu, J., Bai, R., Liu, Y., Zhang, X., Kan, J., and Jin, C. (2018). Isolation, Structural Characterization and Bioactivities of Naturally Occurring PolysaccharidePolyphenolic Conjugates from Medicinal Plants-A Reivew. Int. J. Biol. Macromol. 107 (Pt B), 2242-2250. doi:10.1016/j.ijbiomac.2017.10.097

Liu, J., Zu, M., Chen, K., Gao, L., Min, H., Zhuo, W., et al. (2018). Screening of Neuraminidase Inhibitory Activities of Some Medicinal Plants Traditionally Used in Lingnan Chinese Medicines. BMC Complement. Altern. Med. 18 (1), 102. doi:10.1186/s12906-018-2173-1

Liu, M. P., Liao, M., Dai, C., Chen, J. F., Yang, C. J., Liu, M., et al. (2016). Sanguisorba Officinalis L Synergistically Enhanced 5-fluorouracil Cytotoxicity in Colorectal Cancer Cells by Promoting a Reactive Oxygen Species-Mediated, Mitochondria-caspase-dependent Apoptotic Pathway. Sci. Rep. 6 (2), 34245. doi:10.1038/srep34245

Liu, Y., Nielsen, M., Staerk, D., and Jäger, A. K. (2014). High-resolution Bacterial Growth Inhibition Profiling Combined with HPLC-HRMS-SPE-NMR for Identification of Antibacterial Constituents in Chinese Plants Used to Treat Snakebites. J. Ethnopharmacol. 155 (2), 1276-1283. doi:10.1016/ j.jep.2014.07.019

Liu, Y., Sun, Y., and Huang, G. (2018). Preparation and Antioxidant Activities of Important Traditional Plant Polysaccharides. Int. J. Biol. Macromol. 111 (2017), 780-786. doi:10.1016/j.ijbiomac.2018.01.086

Lkhagvasuren, K., and Kim, J. K. (2019). Ziyuglycoside II Induces Caspasesdependent and Caspases-independent Apoptosis in Human colon Cancer Cells. Toxicol. Vitro 59 (8), 255-262. doi:10.1016/j.tiv.2019.04.028

Ma, J., Meng, X., Guo, X., Lan, Y., and Zhang, S. (2017). Thermal Analysis during Partial Carbonizing Process of Rhubarb, Moutan and burnet. PLoS One 12 (3), e0173946. doi:10.1371/journal.pone.0173946

Mazzio, E. A., and Soliman, K. F. (2017). HTP Nutraceutical Screening for Histone Deacetylase Inhibitors and Effects of HDACis on Tumor-Suppressing miRNAs by Trichostatin a and Grapeseed (Vitis vinifera) in HeLa Cells. Cancer Genomics Proteomics 14 (1), 17-33. doi:10.21873/cgp.20016

Meng, X., Tang, G. Y., Liu, P. H., Zhao, C. J., Liu, Q., and Li, H. B. (2020). Antioxidant Activity and Hepatoprotective Effect of 10 Medicinal Herbs on CCl4-Induced Liver Injury in Mice. World J. Gastroenterol. 26 (37), 5629-5645. doi:10.3748/wjg.v26.i37.5629

Mirgos, M., Przybyszewska, E., Capecka, E., Angielczyk, M., Przybył, J. L., Bączek, K., et al. (2012). Intraspecific Variability of Great burnet (Sanguisorba Officinalis L.) in Respect of Sterols Content. Herba Pol. 58 (3), 16-23.

Mukherjee, P. K., Maity, N., Nema, N. K., and Sarkar, B. K. (2011). Bioactive Compounds from Natural Resources against Skin Aging. Phytomedicine 19 (1), 64-73. doi:10.1016/j.phymed.2011.10.003

Na, E. J., Kim, D. J., Kim, J. H., and Kim, G. R. (2019). Recent Trends in Antiobesity and Anti-inflammatory Studies in Modern Health Care. Technol. Health Care 27, 519-530. doi:10.3233/THC-191736

Nam, S. H., Lkhagvasuren, K., Seo, H. W., and Kim, J. K. (2017). Antiangiogenic Effects of Ziyuglycoside II, a Major Active Compound of Sanguisorba Officinalis L. Phytother Res. 31, 1449-1456. doi:10.1002/ptr.5874

Nguyen, T. T., Cho, S. O., Ban, J. Y., Kim, J. Y., Ju, H. S., Koh, S. B., et al. (2008). Neuroprotective Effect of Sanguisorbae Radix against Oxidative Stress-Induced Brain Damage: In Vitro and In Vivo. Biol. Pharm. Bull. 31 (11), 2028-2035. doi:10.1248/bpb.31.2028

Park, S., Kim, D. S., Kang, S., and Shin, B. K. (2015). Synergistic Topical Application of Salt-Processed Phellodendron Amurense and Sanguisorba Officinalis Linne Alleviates Atopic Dermatitis Symptoms by Reducing Levels of Immunoglobulin E and Pro-inflammatory Cytokines in NC/ Nga Mice. Mol. Med. Rep. 12 (5), 7657-7664. doi:10.3892/ mmr.2015.4348

Paniagua-Zambrana, N. Y., Bussmann, R. W., and Romero, C. (2020). "Sanguisorba minor Scop. Rosaceae," in Ethnobotany of the Andes. Editors N. Y. Paniagua-Zambrana and R. W. Bussmann (Switzerland, FL, Cham: Springer), $1-5$. 
Pawlaczyk-Graja, I., Balicki, S., Ziewiecki, R., Matulová, M., Capek, P., and Gancarz, R. (2016). Polyphenolic-polysaccharide Conjugates of Sanguisorba Officinalis L. With Anticoagulant Activity Mediated Mainly by Heparin Cofactor II. Int. J. Biol. Macromol. 93, 1019-1029. doi:10.1016/ j.ijbiomac.2016.09.082

Ponou, B. K., Teponno, R. B., Ricciutelli, M., Nguelefack, T. B., Quassinti, L., Bramucci, M., et al. (2011). Novel 3-oxo- and 3,24-dinor-2,4-secooleanane-type Triterpenes from Terminalia Ivorensis A. Chev. Chem. Biodivers 8 (7), 1301-1309. doi:10.1002/cbdv.201000145

Ravipati, A. S., Zhang, L., Koyyalamudi, S. R., Jeong, S. C., Reddy, N., Bartlett, J., et al. (2012). Antioxidant and Anti-inflammatory Activities of Selected Chinese Medicinal Plants and Their Relation with Antioxidant Content. BMC Complement. Altern. Med. 12, 173. doi:10.1186/1472$6882-12-173$

Romojaro, A., Botella, M. Á., Obón, C., and Pretel, M. T. (2013a). Nutritional and Antioxidant Properties of Wild Edible Plants and Their Use as Potential Ingredients in the Modern Diet. Int. J. Food Sci. Nutr. 64 (8), 944-952. doi:10.3109/09637486.2013.821695

Romojaro, A., Sanchez-Bel, P., Serrano, M., and Pretel, M. T. (2013b). Wild Edible Plants as Potential Antioxidants in Vegetables Oils. J. Chem. 2013, 1-4. doi:10.1155/2013/4579022013

Romojaro, A., Serrano, M., and Pretel, M. T. (2018). Wild Edible Plants (WEP) as Antioxidant Supplements for Oils and Juices. Acta Hortic. 1194, 1039-1044. doi:10.17660/ActaHortic.2018.1194.148

Sabbatini, A., Jurnatan, Y., Fraatz, M. A., Govori, S., Haziri, A., Millaku, F., et al. (2019). Aroma Characterization of a Wild Plant (Sanguisorba Albanica) from Kosovo Using Multiple Headspace Solid Phase Microextraction Combined with Gas Chromatography-Mass Spectrometry-Olfactometry. Food Res. Int. 120, 514-522. doi:10.1016/j.foodres.2018.10.093

Samson, S. L., and Garber, A. J. (2014). Metabolic Syndrome. Endocrinol. Metab. Clin. North. Am. 43 (1), 1-23. doi:10.1016/j.ecl.2013.09.009

Sanchez-Bel, P., Romojaro, A., Egea, I., and Pretel, M. T. (2015). Wild Edible Plants as Potential Antioxidant or Nutritional Supplements for Beverages Minimally Processed. LWT - Food Sci. Techn. 62 (1), 830-837. doi:10.1016/ j.lwt.2014.06.017

Seo, C. S., Jeong, S. J., Yoo, S. R., Lee, N. R., and Shin, H. K. (2016). Quantitative Analysis and In Vitro Anti-inflammatory Effects of Gallic Acid, Ellagic Acid, and Quercetin from Radix Sanguisorbae. Pharmacogn. Mag. 12 (46), 104-108. doi:10.4103/0973-1296.177908

Seo, D. W., Cho, Y. I., Gu, S., Kim, D. H., Yi, Y. J., and Lee, S. M. (2018). A HotWater Extract of Sanguisorba Officinalis Ameliorates Endotoxin-Induced Septic Shock by Inhibiting Inflammasome Activation. Microbiol. Immunol. 62, 44-54. doi:10.1111/1348-0421.12557

Shao, J., Liu, Z., Wang, L., Song, Z., Chang, H., Han, N., et al. (2017). Screening of the Optimized Prescription from Suqingwan in Terms of its Therapeutic Effect on DSS-Induced Ulcerative Colitis by its Regulation of Inflammatory and Oxidative Mediators. J. Ethnopharmacol. 202 (4), 54-62. doi:10.1016/ j.jep.2017.03.006

Shen, T., He, Y., Sun, G., Liu, W., and Zheng, S. (2008). Studies on Chemical Constituents of Sanguisorba Longifolia Bertol. INDIAN J. Chem. Sect. B-ORGANIC Chem. Incl. Med. Chem. 7, 1600-1604.

Son, D. J., Hwang, S. Y., Kim, M. H., Park, U. K., and Kim, B. S. (2015). Antidiabetic and Hepato-Renal Protective Effects of Ziyuglycoside II Methyl Ester in Type 2 Diabetic Mice. Nutrients 7 (7), 5469-5483. doi:10.3390/nu7075232

Song, J. H., Kim, S. Y., Hwang, G. S., Kim, Y. S., Kim, H. Y., and Kang, K. S. (2019). Sanguiin H-11 from Sanguisorbae Radix Protects HT22 Murine Hippocampal Cells against Glutamate-Induced Death. Bioorg. Med. Chem. Lett. 29, 252-256. doi:10.1016/j.bmcl.2018.11.042

Stojiljković, N., Ilić, S., Stojanović, N., Janković-Veličković, L., Stojnev, S., Kocić, G., et al. (2019). Nanoliposome-encapsulated Ellagic Acid Prevents Cyclophosphamide-Induced Rat Liver Damage. Mol. Cel. Biochem. 458, 185-195. doi:10.1007/s11010-019-03541-8

Su, X. D., Ali, I., Arooj, M., Koh, Y. S., Yang, S. Y., and Kim, Y. H. (2018a). Chemical Constituents from Sanguisorba Officinalis L. And Their Inhibitory Effects on LPS-Stimulated Pro-inflammatory Cytokine Production in Bone MarrowDerived Dendritic Cells. Arch. Pharm. Res. 41 (5), 497-505. doi:10.1007/ s12272-018-1035-1
Su, X. D., Guo, R. H., Li, H. X., Ma, J. Y., Kim, Y. R., Kim, Y. H., et al. (2018b). Antiallergic Inflammatory Components from Sanguisorba Officinalis L. Bioorg. Med. Chem. Lett. 28 (12), 2210-2216. doi:10.1016/j.bmcl.2018.04.033

Su, X. D., Guo, R. H., Yang, S. Y., Kim, Y. H., and Kim, Y. R. (2019). Anti-bacterial Effects of Components from Sanguisorba Officinalis L. On Vibrio Vulnificus and Their Soluble Epoxide Hydrolase Inhibitory Activity. Nat. Prod. Res. 33 (23), 3445-3449. doi:10.1080/14786419.2018.1478825

Sun, W., Zhang, Z. L., Liu, X., Zhang, S., He, L., Wang, Z., et al. (2012). Terpene Glycosides from the Roots of Sanguisorba Officinalis L. And Their Hemostatic Activities. Molecules 17 (7), 7629-7636. doi:10.3390/molecules17077629

Sun, Y., Scruggs, D. W., Peng, Y., Johnson, J. R., and Shukla, A. J. (2004). Issues and Challenges in Developing Long-Acting Veterinary Antibiotic Formulations. Adv. Drug Deliv. Rev. 56 (10), 1481-1496. doi:10.1016/j.addr.2004.02.009

Szejk, M., Poplawski, T., Czubatka-Bienkowska, A., Olejnik, A. K., PawlaczykGraja, I., Gancarz, R., et al. (2017a). A Comparative Study on the Radioprotective Potential of the Polyphenolic Glycoconjugates from Medicinal Plants of Rosaceae and Asteraceae Families versus Their Aglycones. J. Photochem. Photobiol. B 171 (10), 50-57. doi:10.1016/ j.jphotobiol.2017.04.027

Szejk, M., Poplawski, T., Sarnik, J., Pawlaczyk-Graja, I., Czechowski, F., Olejnik, A. K., et al. (2017b). Polyphenolic Glycoconjugates from Medical Plants of Rosaceae/Asteraceae Family Protect Human Lymphocytes against $\gamma$-radiation-induced Damage. Int. J. Biol. Macromol. 94, 585-593. doi:10.1016/j.ijbiomac.2016.10.053

Szejk-Arendt, M., Czubak-Prowizor, K., Macieja, A., Poplawski, T., Olejnik, A. K., Pawlaczyk-Graja, I., et al. (2019). Polyphenolic-polysaccharide Conjugates from Medicinal Plants of Rosaceae/Asteraceae Family Protect Human Lymphocytes but Not Myeloid Leukemia K562 Cells against RadiationInduced Death. Int. J. Biol. Macromol. 156, 1445-1454. doi:10.1016/ j.ijbiomac.2019.11.186

Tamma, P. D., Avdic, E., Li, D. X., Dzintars, K., and Cosgrove, S. E. (2017). Association of Adverse Events with Antibiotic Use in Hospitalized Patients. JAMA Intern. Med. 177 (9), 1308-1315. doi:10.1001/jamainternmed.2017.1938

Tan, Y. H., Shudo, T., Yoshida, T., Sugiyama, Y., Si, J. Y., Tsukano, C., et al. (2019). Ellagic Acid, Extracted from Sanguisorba Officinalis, Induces G1 Arrest by Modulating PTEN Activity in B16F10 Melanoma Cells. Genes Cells 24 (11), 688-704. doi:10.1111/gtc. 12719

The Plant List (2021). Sanguisorba. Available at: http://www.theplantlist.org./tpl1. 1/search?q=Sanguisorba (Accessed August 30, 2021).

Tong, H., Song, J., Zhang, Z., Mao, D., Sun, G., and Jiang, G. (2015). Inhibitory Function of P-Selectin-Mediated Leukocyte Adhesion by the Polysaccharides from Sanguisorba Officinalis. Pharm. Biol. 53 (3), 345-349. doi:10.3109/ 13880209.2014.919597

Vanzani, P., Rossetto, M., De Marco, V., Sacchetti, L. E., Paoletti, M. G., and Rigo, A. (2011). Wild Mediterranean Plants as Traditional Food: A Valuable Source of Antioxidants. J. Food Sci. 76, C46-C51. doi:10.1111/j.17503841.2010.01949.x

Wang, L. N., Qin, L. L., He, J. L., Li, X. H., Cao, Z. X., Gu, Y. C., et al. (2018). Aryltetralin-type Lignan Isolated from Sanguisorba Officinalis. J. Asian Nat. Prod. Res. 21 (10), 999-1004. doi:10.1080/10286020.2018.1487957

Wang, R., Sun, J., Jin, M., Jin, L., Qi, Y., Cao, L., et al. (2019b). A New Triterpenoid and Other Constituents with Cytotoxic Activity from the Roots of Sanguisorba Officinalis L. Nat. Prod. Res. 0, 1-5. doi:10.1080/14786419.2019.1693569

Wang, R., Jin, M., Jin, C., Sun, J., Ye, C., Zong, T., et al. (2019a). Three New Ursanetype Triterpenoids from the Roots of Sanguisorba Officinalis L. And Their Cytotoxic Activity. Phytochemistry Lett. 32 (3), 96-100. doi:10.1016/ j.phytol.2019.05.006

Wang, R., Sun, J., Jin, M., Ye, C., Wang, J., Jin, L., et al. (2020a). Two New Phenolic Glycosides With Anti-Complementary Activity from the Roots of Sanguisorba officinalis L. Nat. Prod. Res., 1-10. doi:10.1080/14786419.2020.1723092

Wang, R., Sun, J., Ye, C., Wang, J., Zong, T., Zhou, W., et al. (2020b). Chemical Constituents Isolated from the Roots of Sanguisorba Officinalis L. And Their Chemotaxonomic Significance. Biochem. Syst. Ecol. 89 (10), 103999. doi:10.1016/j.bse.2019.103999

Wang, X. Q., Peng, Y., Peng, B., Xiao, P.-G., and Liu, Y. (2014). Chemical Constituents of Paraboea Glutinosa. Chem. Nat. Compd. 50 (5), 952-954. doi:10.1007/s10600-014-1130-6 
Wang, Z., Loo, W. T., Wang, N., Chow, L. W., Wang, D., Han, F., et al. (2012). Effect of Sanguisorba Officinalis L on Breast Cancer Growth and Angiogenesis. Expert Opin. Ther. Targets 16 Suppl 1 (1), S79-S89. doi:10.1517/14728222.2011.642371

Wright, G. D. (2017). Opportunities for Natural Products in 21st century Antibiotic Discovery. Nat. Prod. Rep. 34, 694-701. doi:10.1039/c7np00019g

Xiong, Y., Zou, Y., Chen, L., Xu, Y., and Wang, S. (2019). Development and In Vivo Evaluation of Ziyuglycoside I-Loaded Self-Microemulsifying Formulation for Activity of Increasing Leukocyte. AAPS PharmSciTech 20 (3), 101. doi:10.1208/ s12249-019-1313-3

Yang, J. H., Hwang, Y. H., Gu, M. J., Cho, W. K., and Ma, J. Y. (2015). Ethanol Extracts of Sanguisorba Officinalis L. Suppress TNF-A/ifn- $\gamma$-Induced Proinflammatory Chemokine Production in HaCaT Cells. Phytomedicine 22 (14), 1262-1268. doi:10.1016/j.phymed.2015.09.006

Yang, J. H., Yoo, J. M., Cho, W. K., and Ma, J. Y. (2016b). Anti-inflammatory Effects of Sanguisorbae Radix Water Extract on the Suppression of Mast Cell Degranulation and STAT-1/Jak-2 Activation in BMMCs and $\mathrm{HaCaT}$ Keratinocytes. BMC Complement. Altern. Med. 16 (1), 347-348. doi:10.1186/ s12906-016-1317-4

Yang, J. H., Yoo, J. M., Cho, W. K., and Ma, J. Y. (2016a). Ethanol Extract of Sanguisorbae Radix Inhibits Mast Cell Degranulation and Suppresses 2,4Dinitrochlorobenzene-Induced Atopic Dermatitis-like Skin Lesions. Mediators Inflamm. 2016, 2947390. doi:10.1155/2016/2947390

Yasueda, A., Kayama, H., Murohashi, M., Nishimura, J., Wakame, K., Komatsu, K. I., et al. (2020). Sanguisorba Officinalis L. Derived from Herbal Medicine Prevents Intestinal Inflammation by Inducing Autophagy in Macrophages. Sci. Rep. 10 (1), 9972. doi:10.1038/s41598-020-65306-4

Yokozawa, T., and Chen, C. P. (2001). Evidence Suggesting a Nitric OxideScavenging Activity for Traditional Crude Drugs, and Action Mechanisms of Sanguisorbae Radix against Oxidative Stress and Aging. J. Am. Aging Assoc. 24 (1), 19-30. doi:10.1007/s11357-001-0003-7

Yoshida, H., Yamazaki, K., Komiya, A., Aoki, M., Kasamatsu, S., Murata, T., et al. (2018). Inhibitory Effects of Sanguisorba Officinalis Root Extract on HYBID (KIAA1199)-Mediated Hyaluronan Degradation and Skin Wrinkling. Int. J. Cosmet. Sci. 41 (1), 12-20. doi:10.1111/ics.12505

Yu, T., Lee, Y. J., Yang, H. M., Han, S., Kim, J. H., Lee, Y., et al. (2011). Inhibitory Effect of Sanguisorba Officinalis Ethanol Extract on NO and $\mathrm{PGE}_{2}$ Production Is Mediated by Suppression of NF-Kb and AP-1 Activation Signaling cascade. J. Ethnopharmacol. 134 (1), 11-17. doi:10.1016/j.jep.2010.08.060

Yun, M. Y., Bae, E. Y., Lee, S. W., Yim, S. H., Ly, S. Y., and Choi, H. J. (2019). Anti-photoaging Effect of Skin Cream Manufactured with Ziyuglycoside I Isolated from Sanguisorba Officinalis on Ultraviolet B-Induced Hairless Mice. Biosci. Biotechnol. Biochem. 83 (7), 1197-1204. doi:10.1080/ 09168451.2019.1607247

Zbikowska, H. M., Szejk, M., Saluk, J., Pawlaczyk-Graja, I., Gancarz, R., and Olejnik, A. K. (2016). Polyphenolic-polysaccharide Conjugates from Plants of Rosaceae/Asteraceae Family as Potential Radioprotectors. Int. J. Biol. Macromol. 86, 329-337. doi:10.1016/j.ijbiomac.2016.01.090

Zhang, H., Chen, J., and Cen, Y. (2018). Burn Wound Healing Potential of a Polysaccharide from Sanguisorba Officinalis L. In Mice. Int. J. Biol. Macromol. 112, 862-867. doi:10.1016/j.ijbiomac.2018.01.214

Zhang, L., Koyyalamudi, S. R., Jeong, S. C., Reddy, N., Smith, P. T., Ananthan, R., et al. (2012). Antioxidant and Immunomodulatory Activities of Polysaccharides from the Roots of Sanguisorba Officinalis. Int. J. Biol. Macromol. 51 (5), 1057-1062. doi:10.1016/j.ijbiomac.2012.08.019

Zhang, S., Liu, X., Zhang, Z. L., He, L., Wang, Z., and Wang, G. S. (2012). Isolation and Identification of the Phenolic Compounds from the Roots of Sanguisorba Officinalis L. And Their Antioxidant Activities. Molecules 17 (12), 13917-13922. doi:10.3390/molecules 171213917

Zhao, W., Zeng, X., Meng, F., Bi, X., Xu, D., Chen, X., et al. (2019). Structural Characterization and In Vitro-In Vivo Evaluation of Effect of a Polysaccharide from Sanguisorba Officinalis on Acute Kidney Injury. Food Funct. 10 (11), 7142-7151. doi:10.1039/c9fo01891c

Zhao, Z., He, X., Zhang, Q., Wei, X., Huang, L., Fang, J. C., et al. (2017). Traditional Uses, Chemical Constituents and Biological Activities of Plants from the Genus Sanguisorba L. Am. J. Chin. Med. 45, 199-224. doi:10.1142/ S0192415X17500136

Zheng, K., Shen, H., Jia, J., Lu, Y., Zhu, L., Zhang, L., et al. (2017). Traditional Chinese Medicine Combination Therapy for Patients with Steroid-dependent Ulcerative Colitis: Study Protocol for a Randomized Controlled Trial. Trials 18 (1), 8-9. doi:10.1186/s13063-016-1763-9

Zhou, Y. (2014). Research of the Affection of the Raw and the Processed Sanguisorba Officinalis L. On Their Bleeding Time and Coagulation Time of Mice. Lishizhen Med. Materia Med. Res. 25, 6-7.

Zhu, A. K., Zhou, H., Xia, J. Z., Jin, H. C., Wang, K., Yan, J., et al. (2013). Ziyuglycoside II-Induced Apoptosis in Human Gastric Carcinoma BGC-823 Cells by Regulating Bax/Bcl-2 Expression and Activating Caspase-3 Pathway. Braz. J. Med. Biol. Res. 46, 670-675. doi:10.1590/1414-431X20133050

Zhu, H.l., Chen, G., Chen, S.n., Wang, Q.r., Wan, L., and Jian, S.p. (2019). Characterization of Polyphenolic Constituents from Sanguisorba Officinalis L. And its Antibacterial Activity. Eur. Food Res. Technol. 245 (7), 1487-1498. doi:10.1007/s00217-019-03276-2

Zhu, H. L., Chen, G., Chen, S. N., Wang, R. Q., Chen, L., Xue, H., et al. (2020). Changes in Cell Membrane Properties and Phospholipid Fatty Acids of bacillus Subtilis Induced by Polyphenolic Extract of Sanguisorba Officinalis L. J. Food Sci. 85, 2164-2170. doi:10.1111/1750-3841.15170

Zhu, L. J., Chen, L., Bai, C. F., Wu, A. G., Liang, S. C., Huang, F. H., et al. (2020). A Rapid and Sensitive UHPLC-MS/MS Method for the Determination of Ziyuglycoside I and its Application in a Preliminary Pharmacokinetic Study in Healthy and Leukopenic Rats. Biomed. Pharmacother. 123 (9), 109756. doi:10.1016/j.biopha.2019.109756

Zhu, X., Wang, K., Yao, Y., Zhang, K., Zhou, F., and Zhu, L. (2017). Triggering P53 Activation Is Essential in Ziyuglycoside I-Induced Human Retinoblastoma WERI-Rb-1 Cell Apoptosis. J. Biochem. Mol. Toxicol. 32, 1-7. doi:10.1002/ jbt. 22001

Zhu, X., Wang, K., Zhang, K., Huang, B., Zhang, J., Zhang, Y., et al. (2013). Ziyuglycoside II Inhibits the Growth of Human Breast Carcinoma MDA-MB435 Cells via Cell Cycle Arrest and Induction of Apoptosis through the Mitochondria Dependent Pathway. Int. J. Mol. Sci. 14, 18041-18055. doi:10.3390/ijms140918010.3390/ijms140918041

Conflict of Interest: The authors declare that the research was conducted in the absence of any commercial or financial relationships that could be construed as a potential conflict of interest.

The reviewer $(\mathrm{ZN})$ declared a shared affiliation with several of the authors, (PZ, $\mathrm{WZ}$ ), to the handling editor at time of review.

Publisher's Note: All claims expressed in this article are solely those of the authors and do not necessarily represent those of their affiliated organizations, or those of the publisher, the editors and the reviewers. Any product that may be evaluated in this article, or claim that may be made by its manufacturer, is not guaranteed or endorsed by the publisher.

Copyright (c) 2021 Zhou, Li, Chen, Wang, Yang, Wu, Jiang, Liu, Chen, Zou, Zeng and $W u$. This is an open-access article distributed under the terms of the Creative Commons Attribution License (CC BY). The use, distribution or reproduction in other forums is permitted, provided the original author(s) and the copyright owner(s) are credited and that the original publication in this journal is cited, in accordance with accepted academic practice. No use, distribution or reproduction is permitted which does not comply with these terms. 